Staurosporine Analysis and Its

Pharmacokinetics in the Blood of Rats
L. R. Gurley
K. O. Umbarger
J. M. Kim
E. M. Bradbury
B. E. Lehnert 


\section{DISCLAIMER}

This report was prepared as an account of work sponsored by an agency of the United States Government. Neither the United States Government nor any agency thereof, nor any of their employees, make any warranty, express or implied, or assumes any legal liability or responsibility for the accuracy, completeness, or usefulness of any information, apparatus, product, or process disclosed, or represents that its use would not infringe privately owned rights. Reference herein to any specific commercial product, process, or service by trade name, trademark, manufacturer, or otherwise does not necessarily constitute or imply its endorsement, recommendation, or favoring by the United States Government or any agency thereof. The views and opinions of authors expressed herein do not necessarily state or reflect those of the United States Government or any agency thereof. 


\section{DISCLAIMER}

Portions of this document may be illegible in electronic image products. Images are produced from the best available original document. 


\title{
STAUROSPORINE ANALYSIS AND ITS PHARMACOKINETICS IN THE BLOOD OF RATS
}

\author{
by \\ L. R. Gurley, K. O. Umbarger, J. M. Kim, E. M. Bradbury, and B. E. Lehnert
}

\begin{abstract}
Staurosporine (Stsp), a protein kinase inhibitor, has been found to have a differential effect on the proliferation of normal and transformed cells in vitro (Crissman et al., Proc. Nat. Acad. Sci. USA 88 [1991]). Hence, Stsp might be used in cell-cycle-specific cancer therapy to arrest normal proliferating cells in G1, while permitting tumor cells to continue proliferation. The patient could then be treated with a therapeutic agent of maximum toxicity for actively proliferating tumor cells. Essentially nothing is known, however, about the distribution and pharmacokinetics of Stsp in the body.

To facilitate such in vivo investigations of Stsp, we have developed a High-Performance Liquid Chromatography (HPLC) method for measuring the levels of Stsp in blood. Using a rat model, plasma and red blood cells (RBC) containing Stsp are treated with acetone, which precipitates proteins and permits extraction of the Stsp. The acetone extract containing Stsp is diluted 2:1 with aqueous $0.2 \%$ trifluoroacetic acid (TFA) and then subjected to reversed-phase HPLC on a $\mu$ Bondapak C18 column. A linear elution gradient of acetonitrile running from water $/ 0.2 \%$ TFA to acetonitrile/ $0.2 \%$ TFA in $60 \mathrm{~min}$ at $1 \mathrm{ml} / \mathrm{min}$ elutes Stsp as a sharp peak at $35 \mathrm{~min}$ which can be detected by UV absorption at $292 \mathrm{~nm}$. HPLC of plasma spiked with Stsp standards produced a linear calibration curve that can be used to quantify Stsp in blood samples.

Using this analytical method, Stsp was measured in both plasma and RBC of rat blood. In vitro studies in which whole blood was incubated with Stsp indicated that $\mathrm{RBC}$ took up Stsp at a rapid rate, thereby diminishing its concentration in plasma. However, the binding of Stsp to RBC was found to be weak in vitro, resulting in a steady state equilibrium in which an RBC:plasma ratio of 2:1 was maintained over a wide range of Stsp concentrations.

In vivo, Stsp was rapidly sequestered in some other tissue compartment, which rapidly decreased the concentration of Stsp in plasma to nondetectable levels. Using a postchromatography computerized analysis program that amplified the Stsp UV absorption peak from the HPLC, nanogram levels of Stsp were detected in vivo. Using this detection system for pharmacokinetic studies it was found that, in vivo, Stsp had a half-life of $51.6 \mathrm{~min}$ in plasma and $75.3 \mathrm{~min}$ in RBC. Tissue adsorption studies demonstrated that up to $99 \%$ of the Stsp was adsorbed by the heart and lung tissue in one pass through these organs. Extrapolation of the data from these studies suggest that $1-\mu \mathrm{g}$ Stsp injections should produce a 2- to 7-ng/ml plasma Stsp level in vivo which is in the effective range to produce Gl arrest in normal cells. The short half-life of Stsp in plasma indicates that it will be necessary to infuse Stsp at some low level following the initial bolus injection in order to maintain Stsp levels in plasma at the 1- to $10-\mathrm{ng} / \mathrm{ml}$ level for the 2- to 3-day period necessary to achieve $\mathrm{G} 1$ arrest in vivo.
\end{abstract}




\section{INTRODUCTION}

The regulation of mammalian cell proliferation has long been thought to involve kinasemediated mechanisms of protein phosphorylation. ${ }^{1-12}$ In our laboratory, Crissman et al. recently investigated the effects of the general protein kinase inhibitor staurosporine (Stsp) on the proliferation of cultured mammalian cells. ${ }^{13}$ That work demonstrated that Stsp has a differential effect on the cell cycle progression of normal and transformed cells through G1 and $S$ phases. It was found that low levels of Stsp $(10 \mathrm{ng} / \mathrm{ml})$ reversibly arrested nontransformed cells in early G1 phase, while much higher concentrations of Stsp $(50 \mathrm{ng} / \mathrm{ml})$ had no effect on G1 progression and DNA replication in transformed cells. Those studies had major implications for the development of new strategies in cancer diagnosis and therapy. ${ }^{13}$

One of the most interesting of those strategies involved using this drug's capacity to arrest normal cells, but not transformed cells, in G1. According to this strategy, a cancer patient could be treated first with low levels of Stsp to temporarily arrest in G1 the actively proliferating cells of normal tissues such as bone marrow and intestinal mucosa. The patient could then be treated with a therapeutic agent of maximum toxicity for actively proliferating tumor cells. This strategy would allow a far more effective therapeutic dose of tumor-killing agent to be delivered to the proliferating tumor cells because it would reduce harmful side-effects to the normal tissues whose cell proliferation was temporarily inhibited by Stsp, making them insensitive to the toxic therapeutic agent. ${ }^{13}$

To determine the feasibility of this strategy, we administered Stsp to rats to produce G1 arrest in normally proliferating tissues. Flow cytometry analysis of bone marrow cells indicated that G1 arrest was not accomplished. ${ }^{14}$ This suggested that the Stsp was not reaching its target tissues in vivo. From these preliminary studies, it was clear that it would be necessary to assay the level of Stsp in the blood in order to determine the dose levels and time schedules for administering the drug. This paper reports the development of an analysis procedure for Stsp in blood samples and uses the procedure to demonstrate the translocation of Stsp from the plasma to red blood cells (RBC) and other tissue compartments.

\section{METHODS}

Staurosporine: Stsp was obtained from Kamiya (Thousand Oaks, CA). For spectrophotometry and initial chromatography experiments, Stsp was dissolved in dimethyl sulfoxide (DMSO) (J. T. Baker, Phillipsburg, NJ) at a concentration of $0.5 \mu \mathrm{g} / \mathrm{ml}$. This stock solution was then diluted to appropriate concentrations in various solvents, serum, or 
plasma for individual experiments. For fluorescence spectroscopy, Stsp was dissolved in $10 \%$ ethanol at $10 \mu \mathrm{g} / \mathrm{ml}$. In the final stages of the development of the Stsp assay and in the biological experiments that followed, Stsp was dissolved in polyethylene glycol-400 (PEG) (J. T. Baker) at a concentration of $1 \mu \mathrm{g} / \mu \mathrm{l}$. This stock solution was then diluted to appropriate concentrations in various solvents, plasma, or whole blood samples.

Spectrophotometry and Fluorometry: The absorption spectrum of Stsp solutions was obtained using a Gilford Model 250 spectrophotometer equipped with a Model 2430 wavelength scanner and a Model 2451 curette positioner fitted with a single dualcompartment curette containing sample on one side and blank solution on the other. This single beam instrument alternately measured the absorption of the sample and blank using the reciprocating motion of the curette carriage as it scanned the wavelengths. The blank was subtracted electronically from the sample absorption to produce the absorption spectrum.

The fluorescence spectra of Stsp solutions were obtained using a Spex Fluorolog spectrofluorometer, Model F2T2, equipped with a xenon arc lamp, computer controls, and computerized data analysis program. Both excitation spectra and emission spectra are obtained with this instrument, which records the spectra in "counts per second (CPS)." These counts refer to the number of photons given off by the sample that hit the photomultiplier tube detector.

Animals, Blood Collection, and Blood Processing: Adult male Fisher 344 rats, specificpathogen-free, were obtained from Harlan Sprague Dawley, Inc. (Indianapolis, IN). Whole blood to be used for serum, plasma, and $\mathrm{RBC}$ preparations was collected from rats anesthetized with an IP injection of $50 \mathrm{mg}$ sodium pentobarbital. The blood was removed by cardiac puncture, using an unheparinized 10-ml syringe. Generally, 5-7 ml blood was collected per rat. To prepare serum, we placed the blood in an unheparinized centrifuge tube and allowed it to stand $30 \mathrm{~min}$ at room temperature to clot. The sample was then centrifuged at $2000 \mathrm{rpm}$ in a clinical centrifuge for $20 \mathrm{~min}$ and the supernatant serum fluid was removed.

To prepare plasma and $\mathrm{RBC}$, we immediately placed the blood in a 7-ml sterile blood collection tube (Vacutainer) containing either 100 USP units of sodium heparin or $10.5 \mathrm{mg}$ of disodium EDTA (Bacon Dickinson, Rutherford, NJ). The blood was then centrifuged at $800 \mathrm{~g}$ in a clinical centrifuge for $6.5 \mathrm{~min}$. The supernatant plasma fluid was removed with a positive-displacement $250-\mu \mathrm{l}$ micropipetter (Rainin, Emeryville, CA) and placed in a 
separate tube. The hematocrit of rat blood at our altitude is $\sim 50 \%$. Thus, the volumes of plasma and RBC were approximately equal.

To inject Stsp into the rats, we anesthetized the animals using enfluorane in air $(5 \% \mathrm{vol} / \mathrm{vol}$, $21 / \mathrm{min}$ ) and inserted a sterile catheter fitted with a $3-\mathrm{cm}$ silastic tubing tip into the right jugular vein, advancing it so that the tip was placed just above the right atrium of the heart. The tubing was prefilled with a $10 \%$ heparinized saline solution to prevent clotting at the tip. The catheter was attached to a $1-\mathrm{ml}$ syringe and a single bolus injection of $0.2 \mathrm{mg}$ Stsp dissolved in a 1:1 PEG:10\% glucose $/ \mathrm{H}_{2} \mathrm{O}$ solution was administered. A chase solution of $0.5 \mathrm{ml} 10 \%$ glucose $/ \mathrm{H}_{2} \mathrm{O}$ was then injected to clear the catheter dead space $(0.2 \mathrm{ml})$. At $5 \mathrm{~min}$ or $15 \mathrm{~min}$ after injection of Stsp, blood was collected from the rats by withdrawing it from just above the right atrium using the IV catheter inserted in the jugular vein. To prevent clotting, we used a 10-ml syringe prerinsed with heparin solution. The blood was immediately placed in a blood collection tube containing disodium EDTA. Plasma was obtained from these samples as described above.

To measure Stsp adsorbed by only the heart and lungs, we gave rats bolus injections of $500 \mu \mathrm{g}, 250 \mu \mathrm{g}$, or $100 \mu \mathrm{g}$ of Stsp dissolved in $100 \mu \mathrm{l}$ as described above. These injections were made into the superior vena cava leading to the heart. Just before injection, a needle fitted with a withdrawal syringe was inserted into the abdominal aorta and tied off so that no blood could flow past it. The Stsp was immediately injected when the abdominal aorta was tied off and blood was collected in 1- to 2-ml aliquots in EDTA-treated vacuum vials in rapid succession from the abdominal aorta until no more was available. Usually 35 samples were obtained per rat, totaling 5-6 $\mathrm{ml}$ blood per rat. The blood was mixed with the EDTA in the vacuum tubes and then transferred to centrifuge tubes. Its volume was recorded and it was centrifuged to separate plasma from RBC as described above. These samples were then frozen for storage.

High-Performance Liquid Chromatography (HPLC): Reversed-phase HPLC was performed on samples using a $\mu$ Bondapak $C 18$ Radial-PAK flexible walled cartridge (8-mm i.d. $\times 10 \mathrm{~cm}$ ) (Waters Associates, Milford, MA). This cartridge was contained in a Waters Z-Module, which radically compressed the cartridge to produce a uniformly dense, stable column free of void pockets and wall effects. ${ }^{15}$ The water and acetonitrile used in the HPLC system were HPLC grade (J. T. Baker) and the trifluoroacetic acid (TFA) was spectrograde (Pierce Chemical Co., Rockford, IL). 
The HPLC instrument consisted of three Waters Model 6000A solvent delivery pumps attached in series with pump A closest to the column and pump $\mathrm{C}$ the most distant. Pump $\mathrm{C}$ delivered $\mathrm{H}_{2} \mathrm{O}$ containing $0.2 \%$ TFA, pump $\mathrm{B}$ delivered a solution of $50 \% \mathrm{CH}_{3} \mathrm{CN}$ and $50 \% \mathrm{H}_{2} \mathrm{O}$ containing $0.2 \%$ TFA, and pump A delivered $\mathrm{CH}_{3} \mathrm{CN}$ containing $0.2 \%$ TFA. Control of the pump flow rates and the solvent gradients was achieved using a Digital Model 350 computer interfaced with the pumps by a Waters Model 840 system interface module. The UV absorption of the column effluent was monitored at four different wavelengths using a Waters Model 490 multiwavelength flow detector.

Before each HPLC run, the column was equilibrated for 20 min with $\mathrm{H}_{2} \mathrm{O}$ containing $0.2 \%$ TFA (hereafter referred to as $\mathrm{H}_{2} \mathrm{O} / \mathrm{TFA}$ or aqueous $0.2 \%$ TFA) at a flow rate of $1 \mathrm{ml} / \mathrm{min}$. Samples whose volume was less than $2 \mathrm{ml}$ were loaded on the column by injection using a Waters U6K injector. Samples greater than $2 \mathrm{ml}$ were loaded by dipping the intake line of the pump into the sample tube and pumping the sample through the column at $1 \mathrm{ml} / \mathrm{min}$. To ensure quantitative transfer of the entire sample into the column, we added $5 \mathrm{ml} \mathrm{H}_{2} \mathrm{O} / \mathrm{TFA}$ to the empty sample tube and pumped it through the column to rinse the tube, pump, and pump lines. Following this loading, the pumping of $\mathrm{H}_{2} \mathrm{O} / \mathrm{TFA}$ was continued until the column effluent absorbance at $292 \mathrm{~nm}$ was less than 1 .

Stsp was eluted from the column with a linear gradient of acetonitrile in $\mathrm{H}_{2} \mathrm{O} / \mathrm{TFA}$ that progressed from $\mathrm{H}_{2} \mathrm{O}$ /TFA to $\mathrm{CH}_{3} \mathrm{CN}$ containing $0.2 \%$ TFA (hereafter referred to as $\mathrm{CH}_{3} \mathrm{CN} / \mathrm{TFA}$ ) in $60 \mathrm{~min}$ at a flow rate of $1 \mathrm{ml} / \mathrm{min}$. This was achieved by programming a linear gradient running from $100 \%$ pump $\mathrm{C}$ to $100 \%$ pump $\mathrm{B}$ in $30 \mathrm{~min}$ and from $100 \%$ pump $\mathrm{B}$ to $100 \%$ pump $\mathrm{A}$ in $30 \mathrm{~min}$. This pump arrangement eliminated the mixing of $\mathrm{H}_{2} \mathrm{O}$ TFA directly with $\mathrm{CH}_{3} \mathrm{CN} / \mathrm{TFA}$, which produces baseline oscillation artifacts. ${ }^{16} \mathrm{At}$ the end of each run, the column was returned to the initial solvent conditions using a rapid 10-min linear gradient. The column was then equilibrated for the next run with $\mathrm{H}_{2} \mathrm{O} / \mathrm{TFA}$ for $20 \mathrm{~min}$.

Standard Procedure Developed for Staurosporine Analysis: Blood was collected in tubes containing disodium EDTA. For in vitro experiments, Stsp dissolved in PEG was added, and the whole blood was incubated $15 \mathrm{~min}$ in a $37^{\circ} \mathrm{C}$ water bath. The blood was then centrifuged at room temperature and the plasma was removed from the RBC as described above. Using a positive-displacement $250-\mu 1$ micropipetter, $0.1 \mathrm{ml}$ of either plasma or RBC was placed in a $12-\mathrm{ml}$ glass centrifuge tube and $1 \mathrm{ml}$ acetone was added, which precipitated the proteins immediately. The mixture was stirred with a glass rod and centrifuged at $800 \mathrm{~g}$ for $5 \mathrm{~min}$. The supernatant acetone containing the Stsp was 
withdrawn and placed in another tube. The precipitate was washed twice with $0.5 \mathrm{ml}$ acetone, and the wash acetone was recovered and added to the original extract. The acetone extract was diluted with $4.5 \mathrm{ml} \mathrm{H}_{2} \mathrm{O} / \mathrm{TFA}$. This 6.6- $\mathrm{ml}$ sample was then pumped through the HPLC at $1 \mathrm{ml} / \mathrm{min}$ followed by a $5-\mathrm{ml} \mathrm{H}_{2} \mathrm{O} / \mathrm{TFA}$ tube rinse. The column was flushed isocratically with $\mathrm{H}_{2} \mathrm{O} /$ TFA for another 12 min, which pumped out the acetone. Stsp was then eluted with a $60-\mathrm{min}$ linear gradient of acetonitrile as described above. The Stsp peak detected at $292 \mathrm{~nm}$ was recorded in the computer. The area under this peak was quantified using the data processing program of the Waters 840 Data and Chromatography Control Station. The area under the peak was then converted to micrograms of Stsp using a standard curve.

Detection of Staurosporine In the Nanogram Range: Measuring Stsp in vivo usually required working with blood samples containing nanogram quantities of Stsp. During the course of this work we discovered that nanogram-size Stsp peaks were detected at $292 \mathrm{~nm}$ by the Waters Model 490 flow detector even though they were too small to be recorded above background during the chromatography. The data for these peaks was stored in the Digital Model 350 computer and could be accessed using the "scanner" postchromatography data processing program. To do this, we specified the time region where Stsp was expected (36-38 $\mathrm{min})$ and greatly expanded the absorbance scale in that region until the peak could be visualized. No significant background noise was detected. The exact time range of the peak was then specified and the area of the peak was quantified using the "scanner" program. The area was then converted to nanograms Stsp using a standard curve.

\section{EXPERIMENTAL}

Spectrophotometry of Staurosporine: The first objective of this project was to develop a quick and simple method for measuring Stsp in rat blood. Spectrophotometric analysis was explored as a method of detection. When Stsp was dissolved in DMSO, it was found to have a strong absorbance peak at $296 \mathrm{~nm}$ and a weaker peak at $335 \mathrm{~nm}$ (Fig. 1A). However, when Stsp was dissolved in rat serum at a concentration of $17.5 \mu \mathrm{g} / \mathrm{ml}$, the absorbance of serum at $296 \mathrm{~nm}$ was so great that the Stsp could not be detected above the high background (Fig. 1B). The absorbance of Stsp could be detected above that of serum at $335 \mathrm{~nm}$ (Fig. 1B), but the background absorbance was considered to be too high for detection of the low concentrations of Stsp expected in our in vivo experiments $(5 \mathrm{ng} / \mathrm{ml}$ to $20 \mu \mathrm{g} / \mathrm{ml})$. 

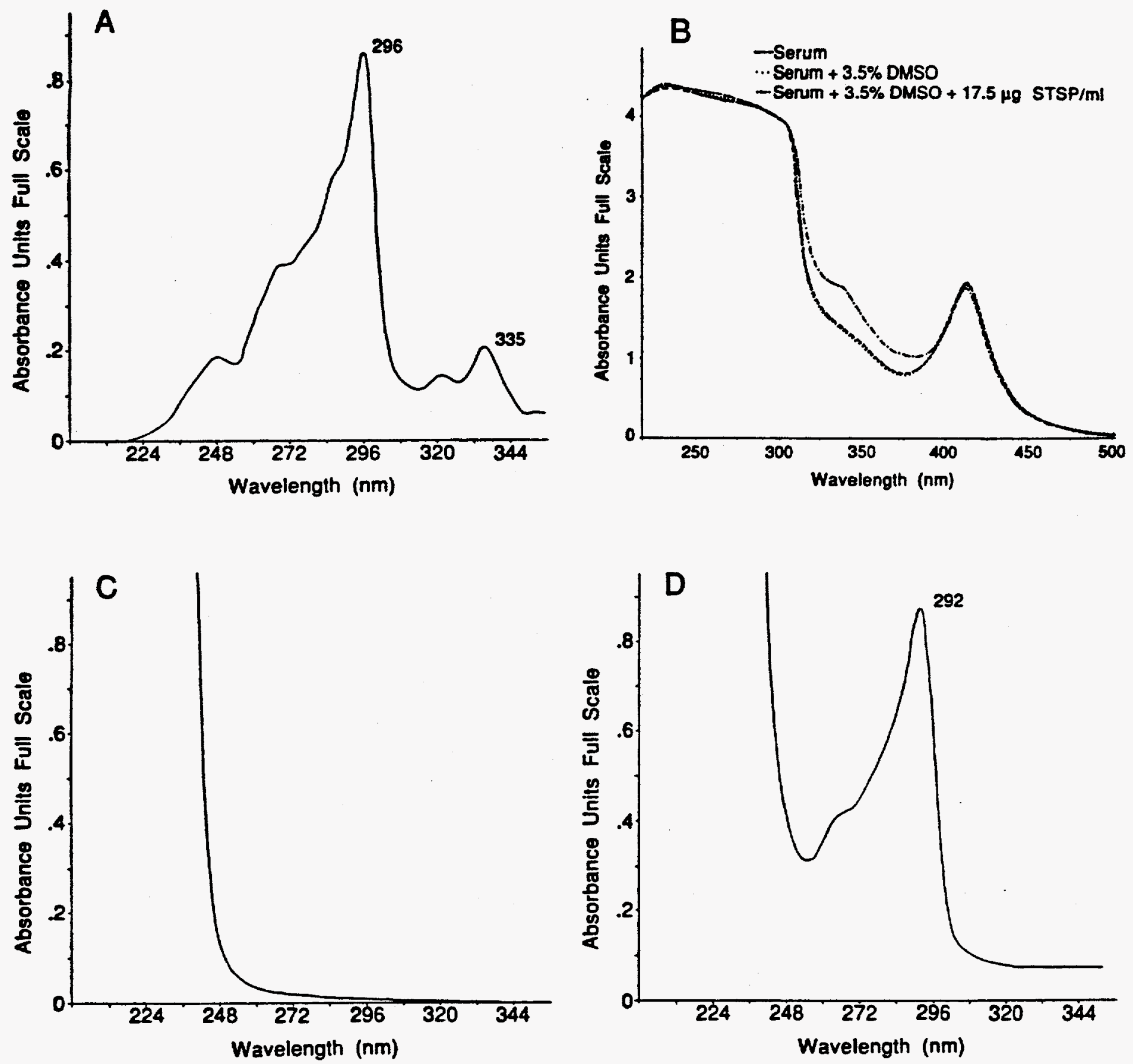

Figure 1. Spectrophotometry of Staurosporine. (A) Absorbance of $5 \mu \mathrm{g} \mathrm{Stsp/ml} \mathrm{DMSO}$ using DMSO as a blank. (B) Absorbance of serum (---), serum + 3.5\% DMSO (...), and $17.5 \mu \mathrm{g} \mathrm{Stsp} / \mathrm{ml}$ of serum + 3.5\% DMSO using air as a blank. (C) Absorbance of $10 \mu \mathrm{l}$ DMSO in $92 \%$ acetonitrile containing $0.2 \%$ TFA using $92 \%$ acetonitrile/ $0.2 \%$ TFA as a blank. (D) Absorbance of $5 \mu \mathrm{g}$ Stsp/10 $\mu 1$ DMSO in $92 \%$ acetonitrile/ $0.2 \%$ TFA using $92 \%$ acetonitrile/ $0.2 \%$ TFA as a blank. 
Fluorometry of Staurosporine: Since fluorescence is generally a more sensitive method of detection than absorbance, the fluorescence spectrum of Stsp was examined. When Stsp was dissolved in $10 \%$ ethanol at $10 \mu \mathrm{g} / \mathrm{ml}$, three peaks of fluorescence were observed between $350 \mathrm{~nm}$ and $450 \mathrm{~nm}$ (Fig. 2A). When Stsp was dissolved in DMSO and added to serum at a concentration of $0.5 \mu \mathrm{g} / \mathrm{ml}$, the Stsp fluorescence was barely detected above the high background fluorescence of the serum at $375 \mathrm{~nm}$ (Fig. 2B). The same results were obtained with plasma. From these studies, it was concluded that measuring the fluorescence of Stsp directly in blood samples was also impractical.

Since serum constituents interfered with the detection of Stsp, we decided to remove the serum proteins and see if the Stsp could then be detected in the deproteinized fluid. In previous work, we had found that proteins could be effectively removed by acetone precipitation, ${ }^{17}$ so we treated serum with 10 volumes of acetone and removed the protein precipitate by centrifugation. Fluorescence measurements on the acetone supernatant fluid from serum indicated that $50 \mathrm{ng} / \mathrm{ml}$ of Stsp in the acetone could not be detected (Fig. 2C). Since this is above the concentration range of Stsp found to be effective in tissue culture cells, ${ }^{13}$ it was concluded that fluorescence measurements of Stsp directly on acetone deproteinized samples was also not possible.

HPLC of Staurosporine in Plasma: The above experiments indicated that simple direct measurements of Stsp in blood samples was not possible and that the following things would have to be accomplished if low concentrations of Stsp in blood samples were to be analyzed:

1. The Stsp would have to be separated from the plasma proteins that interfere with detection.

2. The Stsp would have to be separated from the soluble, low molecular weight plasma constituents that interfere with detection.

3. The Stsp would have to be separated from the reagents used to solubilize the Stsp (DMSO, ethanol, acetone, etc.) and from the reagents used to deproteinize the plasma, any of which might interfere with detection.

4. The Stsp would have to be concentrated into a small volume to raise its concentration to detectable levels. 

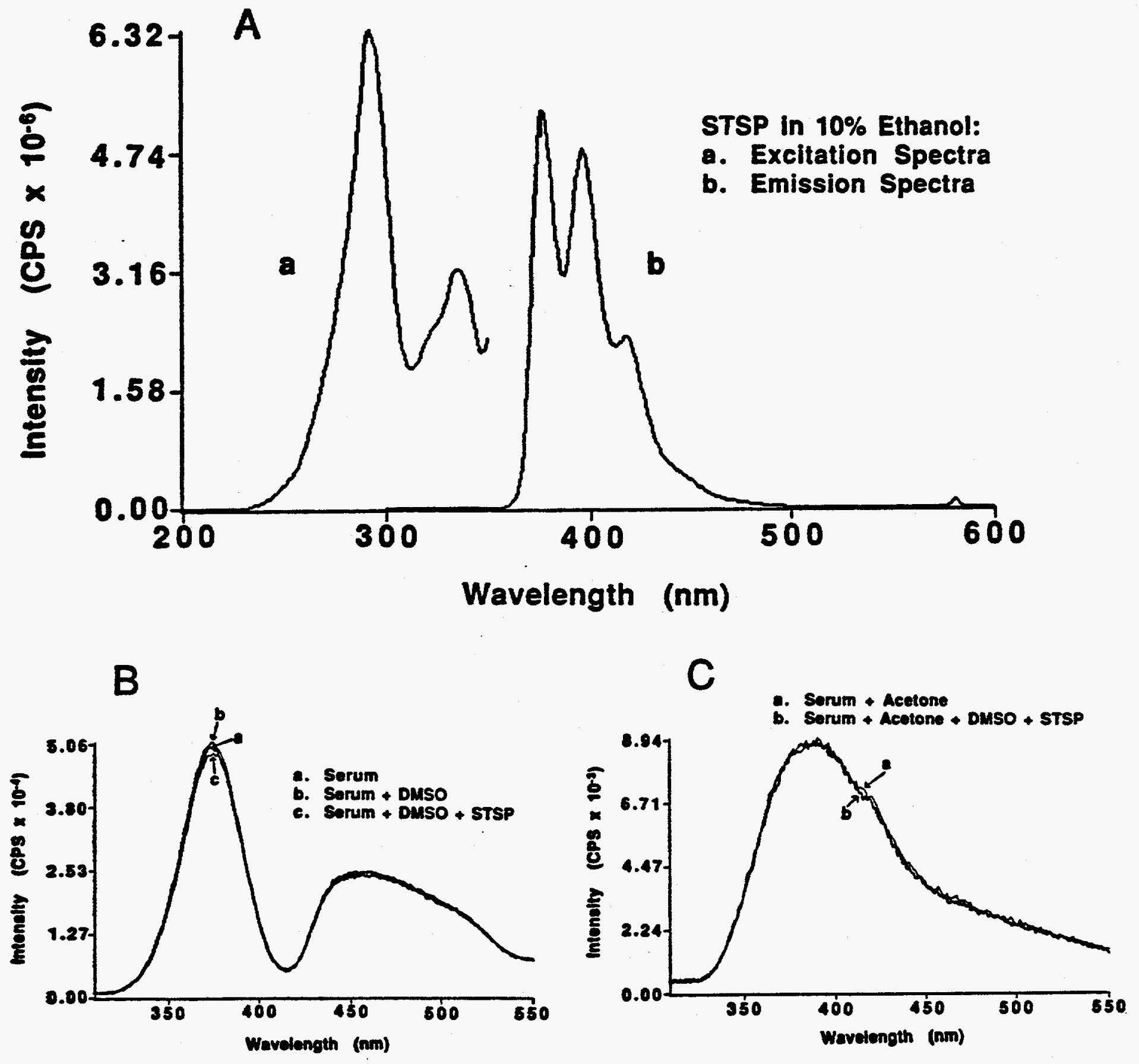

Figure 2. Fluorometry of Staurosporine. (A) Fluorescence spectra of $10 \mu \mathrm{g} \mathrm{Stsp} / \mathrm{ml}$ in $10 \%$ ethanol: (a) excitation spectrum with emission set at $377 \mathrm{~nm}$, (b) emission spectrum with excitation set at $292 \mathrm{~nm}$. (B) Fluorescence spectra of (a) serum, (b) serum with $2.5 \%$ DMSO, and (c) $0.5 \mu \mathrm{g} \mathrm{Stsp} / \mathrm{ml}$ in serum with $2.5 \%$ DMSO, when excitation is set at $292 \mathrm{~nm}$. (C) Fluorescence spectra of (a) an acetone extract of serum, and (b) an acetone extract of serum containing $50 \mathrm{ng} \mathrm{Stsp} / \mathrm{ml}$ and $0.23 \%$ DMSO when excitation is set at $292 \mathrm{~nm}$. 
From our experience, we have found that reversed-phase HPLC is well suited for these tasks. ${ }^{18-22}$ Therefore, we initiated experiments to find appropriate HPLC conditions so that this technology could be used to analyze Stsp. An elution solvent commonly used for reversed-phase HPLC is acetonitrile containing trifluoroacetic acid (TFA). To determine if Stsp could be detected in this solvent, we measured the absorption spectrum of $5 \mu \mathrm{g}$ Stsp/10 $\mu \mathrm{l}$ DMSO dissolved in $92 \%$ acetonitrile containing $0.2 \%$ TFA (Fig. 1D). The high absorption below $250 \mathrm{~nm}$ was found to be due to DMSO (Fig. 1C). However, the background absorption was very low at $296 \mathrm{~nm}$, the expected absorption peak of Stsp (Fig. 1C). When Stsp was added to this solvent at a concentration of $5 \mu \mathrm{g} / \mathrm{ml}$, the Stsp was detected with good sensitivity with its maximum absorbance downshifted slightly to $292 \mathrm{~nm}$ (Fig. 1D).

To determine the elution conditions of Stsp from a reversed-phase HPLC column, we injected $5 \mu \mathrm{g}$ Stsp dissolved in $10 \mu \mathrm{l}$ DMSO into a $\mu$ Bondapak C18 column equilibrated with water containing $0.2 \%$ TFA. Elution of the Stsp was accomplished with a linear gradient of acetonitrile in aqueous $0.2 \%$ TFA that increased from $0 \%$ to $100 \%$ acetonitrile in $60 \mathrm{~min}$. Using a multiwavelength UV monitor, Stsp was detected eluting at $36 \mathrm{~min}$ in approximately $60 \%$ acetonitrile (Fig. 3, A-C). As expected from the spectral analysis in Fig. 1, detection of Stsp was about $25 \%$ better at $292 \mathrm{~nm}$ (Fig. 3A) than at the $280 \mathrm{~nm}$ wavelength usually used for protein detection (Fig. 3B). Detection of Stsp at $215 \mathrm{~nm}$, another wavelength frequently used for protein detection ${ }^{18}$ was only one-third that at $292 \mathrm{~nm}$ (Fig. 3C). DMSO, in which the Stsp was dissolved, was eluted in the first $10 \mathrm{~min}$ and detected only at $215 \mathrm{~nm}$ (Fig. 3C).

To determine if Stsp could be fractionated from plasma proteins by this HPLC method, we injected $1 \mathrm{ml}$ of whole plasma into the system. The bulk of the plasma components eluted between 30 and $45 \mathrm{~min}$ (Fig. 3, D-F). Detection of the plasma proteins was greatest at $215 \mathrm{~nm}$ (Fig. 3F) and much less at $280 \mathrm{~nm}$ (Fig. 3E). While protein detection at $292 \mathrm{~nm}$ was only one-third that at $280 \mathrm{~nm}$ (Fig. 3E), the proteins eluting at $292 \mathrm{~nm}$ coincided with the elution of Stsp (Fig. 3A). From these experiments, it was concluded that Stsp could be detected by UV absorption in HPLC effluents, but the Stsp would have to be separated from the plasma proteins before it could be reliably quantified.

HPLC of Staurosporine in Acetone Extracts: To determine if Stsp could be extracted from plasma and detected by reversed-phase HPLC, we performed the following experiments. A solution of $25 \mu \mathrm{g}$ Stsp dissolved in $50 \mu \mathrm{l}$ of DMSO $(0.5 \mu \mathrm{g} / \mu \mathrm{l})$ was 

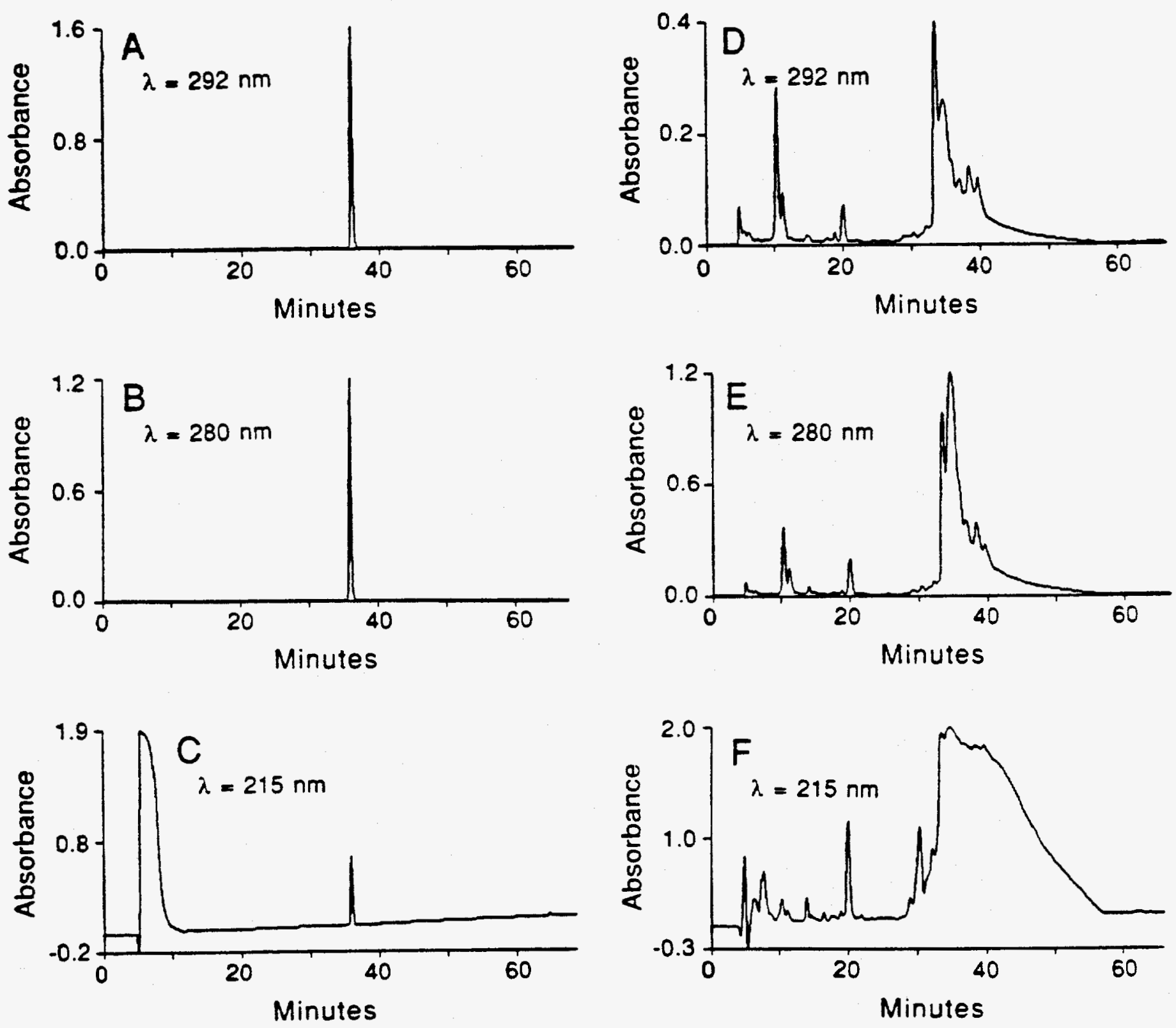

Figure 3. Comparison of the UV absorption profiles of staurosporine and plasma proteins eluted from an HPLC C18 reversed-phase column with a linear gradient of acetonitrile in aqueous $0.2 \%$ TFA. (A-C) A solution of $5 \mu \mathrm{g}$ Stsp in $10 \mu \mathrm{l}$ DMSO was injected into the HPLC and the eluted components were detected at (A) $292 \mathrm{~nm}$, (B) $280 \mathrm{~nm}$, and (C) $215 \mathrm{~mm}$. (D-F) A 1-ml sample of whole plasma was injected into the HPLC and the eluted components were detected at (D) $292 \mathrm{~nm}$, (E) $280 \mathrm{~nm}$, and (F) $215 \mathrm{~nm}$. 
added to $100 \mu$ l plasma, and $1000 \mu$ lacetone was added to precipitate the plasma proteins. The proteins were removed by centrifugation and the supernatant acetone was injected into the HPLC column. The Stsp was eluted after $30 \mathrm{~min}$ (Fig. 4C). No other substance was detected at $292 \mathrm{~nm}$ except a large amount of material eluting in the first $10 \mathrm{~min}$. All the acetone, DMSO, and acetone-soluble plasma constituents were eluted in this initial peak (Fig. 4A). Monitoring the chromatography of the plasma acetone extract at $215 \mathrm{~nm}$ demonstrated that no proteins were eluted between 30 and $45 \mathrm{~min}$ in the chromatogram; that is, the acetone treatment had precipitated all the plasma proteins and none were solubilized to interfere with Stsp elution or detection after $30 \mathrm{~min}$ (Fig. 4B).

The acetone precipitated proteins were washed twice with $500 \mu \mathrm{l}$ acetone and this $1000 \mu \mathrm{l}$ of acetone was injected into the HPLC. A small amount of Stsp was detected (Fig. 4D), amounting to about $12 \%$ of the amount initially extracted in Fig. 4C. Thus, washing the protein precipitate and adding the wash to the initial extract is necessary for quantitative recovery.

Recovery of Staurosporine from Acetone: While it was apparent that Stsp could be detected in the acetone extracts of plasma (Fig. 4C), there was concern that the Stsp might not be quantitatively adsorbed on the reversed-phase C 18 column in the presence of an organic solvent such as acetone. To determine if such solvent solubility losses did occur, we added $25 \mu \mathrm{g}$ Stsp dissolved in $50 \mu \mathrm{l}$ DMSO to $1 \mathrm{ml}$ acetone and subjected the solution to HPLC (Fig. 5A). When this was compared with the HPLC of $25 \mu \mathrm{g}$ Stsp in DMSO added to $11 \mathrm{ml}$ of aqueous $0.2 \%$ TFA (Fig. 5B), it was found that only half of the Stsp was recovered from the acetone sample, even though the volume of the acetone sample was much smaller than that of the aqueous sample. Thus, it appeared that the acetone was not sufficiently polar to promote efficient adsorption of Stsp on the C 18 column.

In the past, we have found that such solubility losses can be eliminated by simply diluting the organic solvent with water to the point that the polarity of the sample solvent is increased sufficiently to promote total adsorption of the analyte to the column. ${ }^{18}$ When the $1-\mathrm{ml}$ acetone sample in Fig. 5A was added to $10 \mathrm{ml}$ of aqueous $0.2 \%$ TFA and this 1:10 diluted sample was subjected to HPLC, all the Stsp was recovered (Fig. 5C). This demonstrated that dilution of the acetone extracts of plasma would be necessary for quantitative loading of Stsp on the C18 column.

The disadvantage of the 1:10 dilution was that it produced a large sample volume $(11 \mathrm{ml})$. To determine if smaller dilutions could he used, we repeated the above experiment using $10: 1,5: 1$, and $2: 1$ dilutions. These experiments were conducted with samples in which 

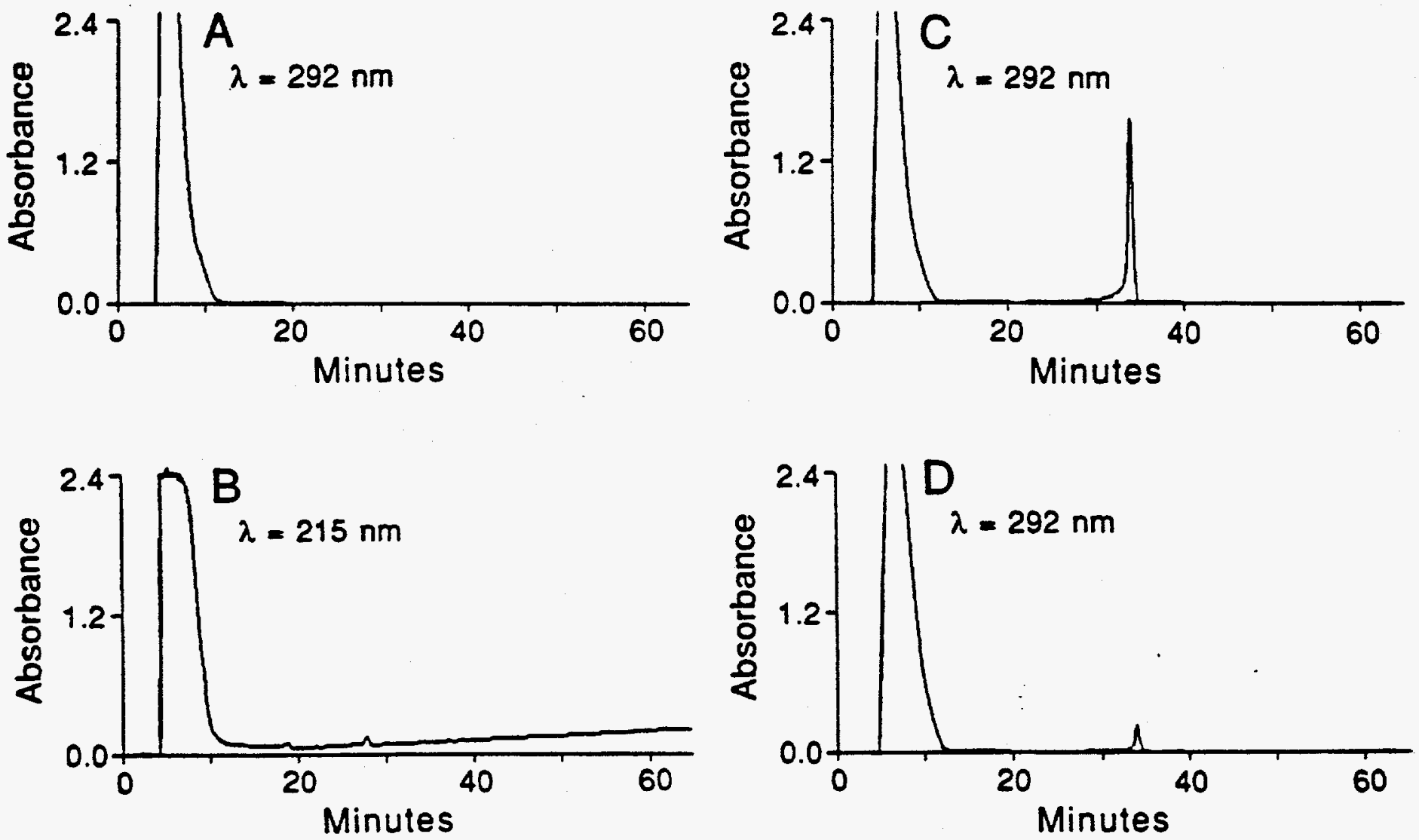

Figure 4. HPLC of acetone extracts of plasma containing staurosporine. (A-B) The proteins in a plasma sample containing $4.5 \%$ DMSO were removed by acetone precipitation and the acetone extract was injected into the HPLC. The eluted components were detected by UV absorption at (A) $292 \mathrm{~nm}$ and (B) $215 \mathrm{~nm}$. (C) The proteins in a plasma sample containing $25 \mu \mathrm{g}$ Stsp and $4.5 \%$ DMSO were removed by acetone precipitation and the acetone extract was injected into the HPLC. The eluted components were detected at $292 \mathrm{~nm}$. (D) The precipitated proteins from the plasma sample in (C) were washed twice with acetone and the acetone extract was injected into the HPLC. The eluted components were detected at $292 \mathrm{~nm}$. 

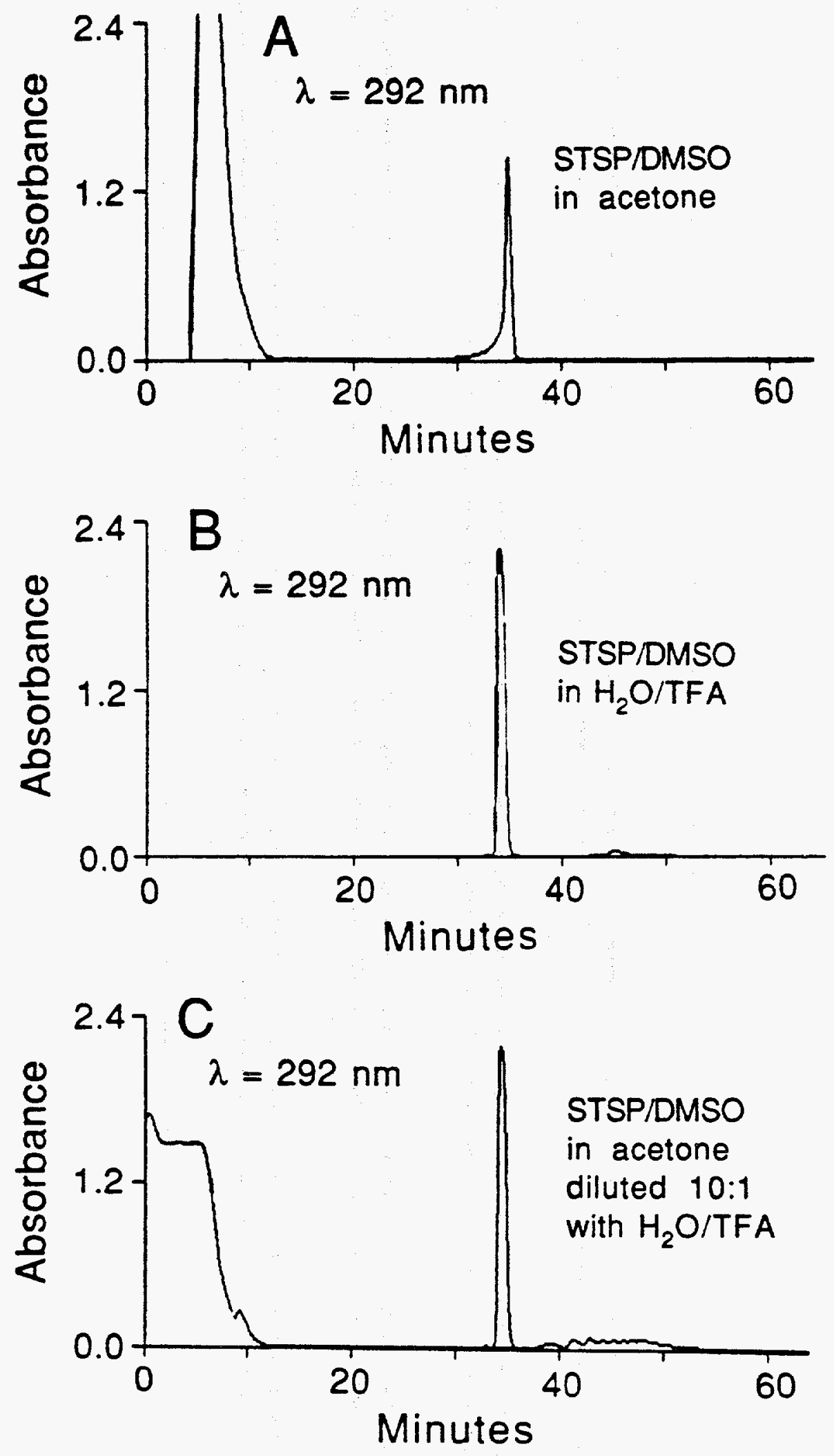

Figure 5. Effect of solvent polarity on staurosporine loading on the reversed-phase HPLC column. A $25 \mu \mathrm{g}$ Stsp/50 $\mu$ I DMSO sample was added to (A) $1 \mathrm{ml}$ acetone, (B) $11 \mathrm{ml}$ aqueous $0.2 \%$ TFA, and (C) $1 \mathrm{ml}$ acetone plus $10 \mathrm{ml}$ aqueous $0.2 \%$ TFA. These samples were injected into the HPLC and the eluted components were detected by UV absorption at $292 \mathrm{~nm}$. 
Stsp was added to plasma or to solutions of aqueous $0.2 \%$ TFA and acetone (Fig. 6). It was found that the recovery of Stsp from samples containing $>90 \%$ acetone $\left(<10 \% \mathrm{H}_{2} \mathrm{O}\right)$ was only $39 \%$ of those diluted to $>64 \%$ aqueous $0.2 \%$ TFA. The extraction of the Stsp from the plasma with the acetone appeared to be complete since the plasma acetone extracts gave the same quantitative results as the samples dissolved directly in acetone. From these results, we concluded that a dilution of one part acetone sample with two parts aqueous $0.2 \%$ TFA was sufficient to promote maximum adsorption of Stsp to the C18 column. Therefore, the 2:1 dilution step was incorporated into the sample preparation protocol.

HPLC of Staurosporine in PEG, Heparin, and EDTA: At this point in the development of the HPLC method, the solvent used to dissolve Stsp was changed from DMSO to polyethylene glycol (PEG), which would cause fewer toxic effects in vivo. To determine if PEG interfered with Stsp chromatography, we dissolved $3.5 \mu 1$ PEG in $1 \mathrm{ml}$ aqueous $0.2 \%$ TFA and subjected the solution to reversed-phase HPLC. During the acetonitrile elution, PEG could not be detected at $292 \mathrm{~nm}$ (Fig. 7A), and only small peaks were detected at $215 \mathrm{~nm}$ eluting in the void volume at $<10 \mathrm{~min}$ and at $57 \mathrm{~min}$ (Fig. 7B). Next, $10 \mu \mathrm{g}$ Stsp in $10 \mu \mathrm{l}$ PEG was dissolved in $100 \mu \mathrm{l}$ plasma and the proteins were precipitated with $1 \mathrm{ml}$ acetone. The proteins were removed from the acetone by centrifugation and the protein pellet was washed twice with $0.5 \mathrm{ml}$ acetone, which was added to the original acetone extract. This acetone sample was then diluted $2: 1$ with aqueous $0.2 \%$ TFA and the $\sim 6-\mathrm{ml}$ sample was injected into the HPLC. Stsp was eluted after $30 \mathrm{~min}$ and appeared in the quantity expected at $292 \mathrm{~nm}$ (Fig. 7C). No additional material eluting with Stsp could be detected at $215 \mathrm{~nm}$ (Fig. 7D). From these experiments, it was concluded that PEG would not interfere with the analysis of Stsp.

Heparin and EDTA are commonly used to prevent clotting during blood collection and plasma preparation. To determine if heparin interfered with Stsp analysis, we dissolved $100 \mu \mathrm{l} 0.15 \mathrm{M} \mathrm{NaCl}$ containing 1000 units heparin/ml in $1 \mathrm{ml}$ aqueous $0.2 \%$ TFA. This 100-unit sample was mixed with $10 \mu \mathrm{g}$ Stsp in PEG and subjected to HPLC. The expected amount of Stsp was detected at $292 \mathrm{~nm}$ and no heparin could be detected at this wavelength (Fig. 8A). However, a large heparin peak was detected at $215 \mathrm{~nm}$ eluting just ahead of Stsp (Fig. 8B). Injection of four times less heparin (25 units) gave a similar size heparin peak detected at $215 \mathrm{~nm}$, indicating that much of the heparin was not eluted from the column. Following these experiments, Stsp samples eluted from the column early (at $27 \mathrm{~min}$ ), indicating the heparin had fouled the column irreversibly. From these experiments, it was concluded that the use of heparin should be avoided during blood sample collection. 


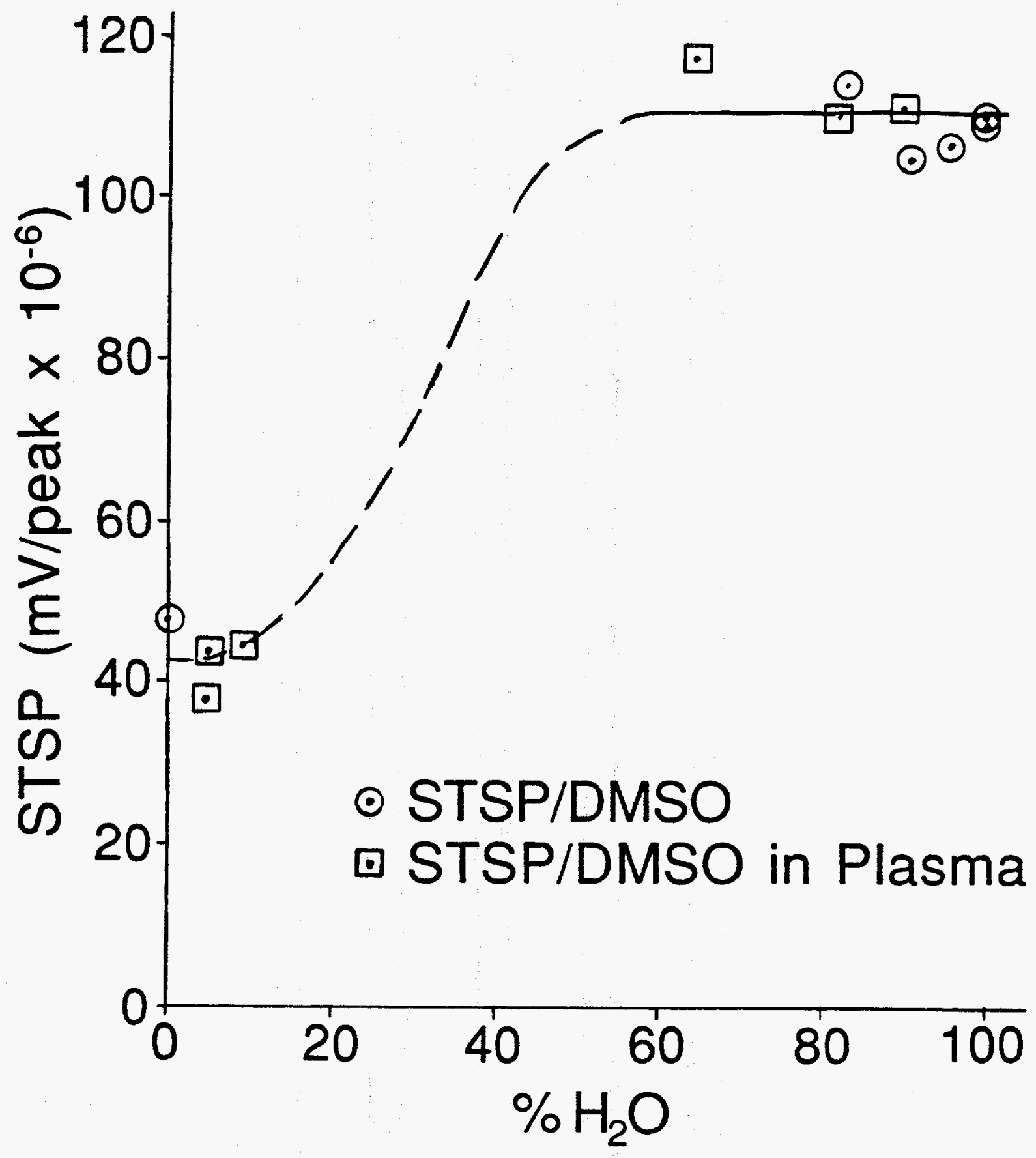

Figure 6. Effect of the water composition of the sample on staurosporine recovery from the reversed-phrase C 18 column. 

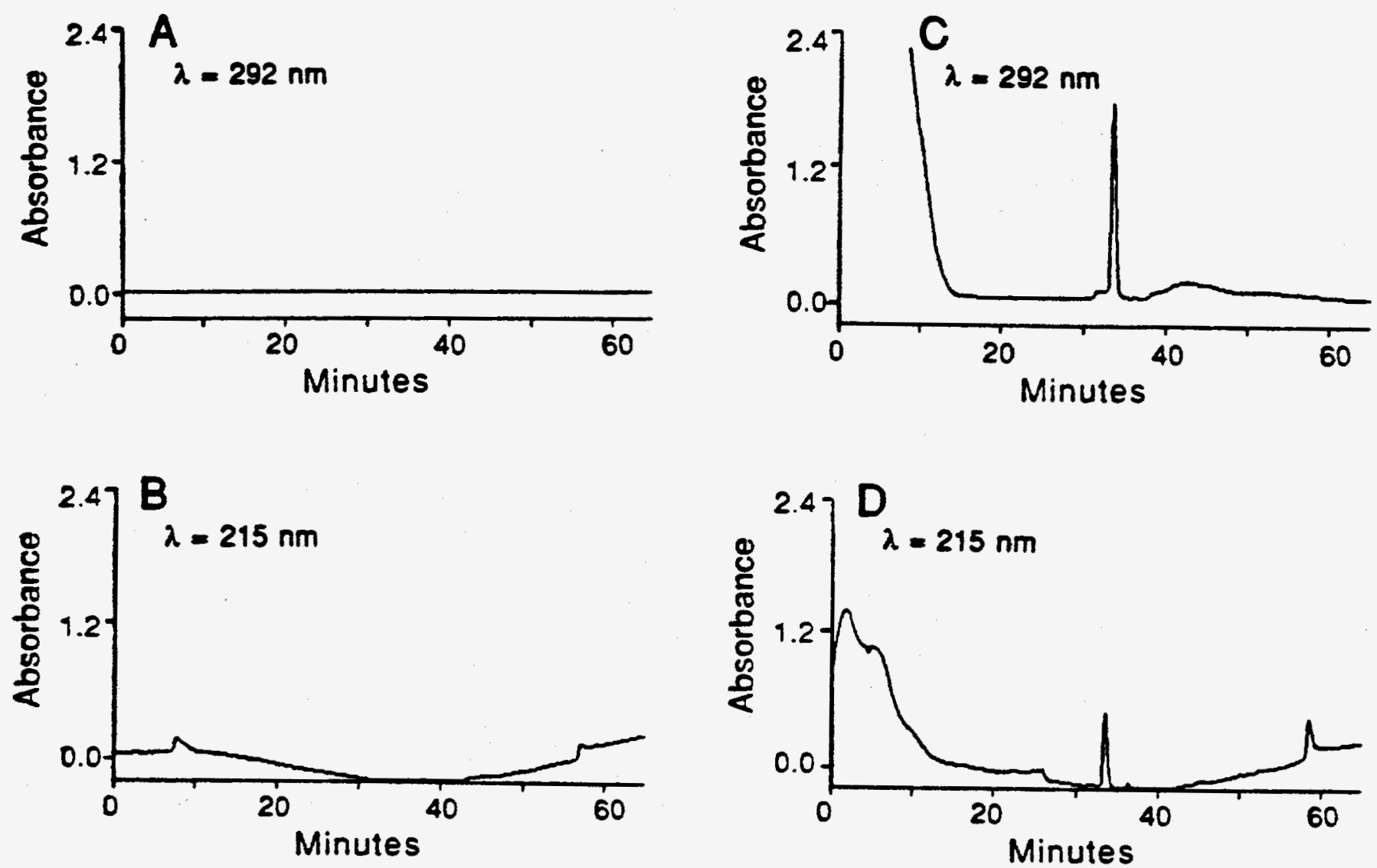

Figure 7. HPLC of staurosporine dissolved in PEG. (A and B) A 1-ml sample of $3.5 \mu l$ PEG dissolved in aqueous $0.2 \%$ TFA was injected into the $C 18$ column. Eluted components were detected at (A) $292 \mathrm{~nm}$ and (B) $215 \mathrm{~nm}$ by UV absorption.

(C and D) A sample containing $10 \mu \mathrm{g}$ Stsp/10 $\mu \mathrm{l}$ PEG was added to $100 \mu \mathrm{l}$ plasma. The Stsp was recovered as an acetone extract, which was diluted $2: 1$ with aqueous $0.2 \%$ TFA and injected into the C18 column. Eluted components were detected at (C) $292 \mathrm{~nm}$ and (D) $2.15 \mathrm{~nm}$ by UV absorption. 

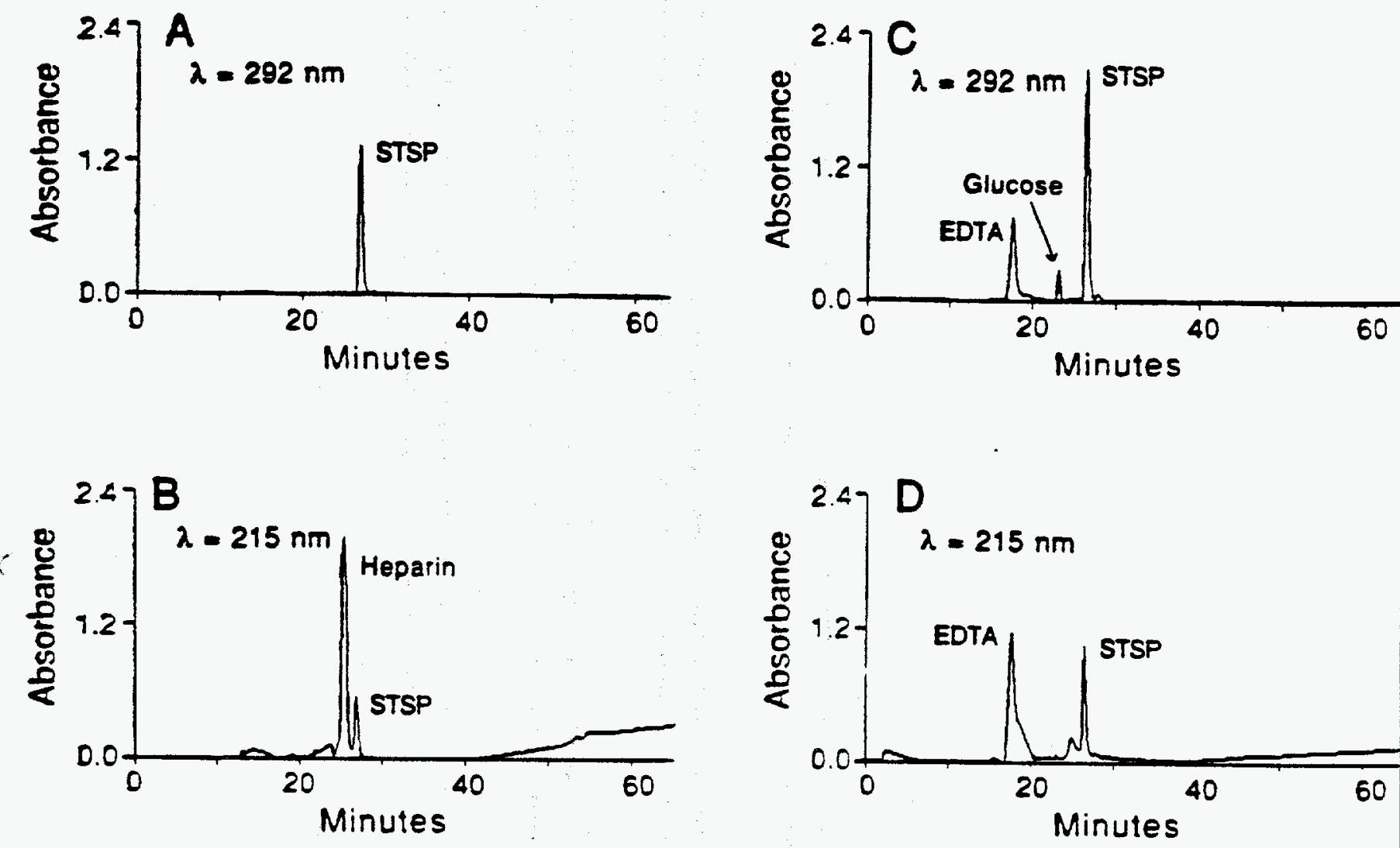

Figure 8. Effects of heparin and EDTA on the HPLC of staurosporine. (A and B) A 1-ml sample of aqueous $0.2 \%$ TFA containing both 100 units of heparin dissolved in $0.1 \mathrm{ml}$ $0.15 \mathrm{M} \mathrm{NaCl}$ and $10 \mu \mathrm{g}$ Stsp dissolved in $10 \mu \mathrm{l}$ PEG was injected into the $\mathrm{C} 18$ column. Eluted components were detected at (A) $292 \mathrm{~nm}$ and (B) $215 \mathrm{~nm}$ by UV absorption. (C and D) A $1-\mathrm{ml}$ sample of aqueous $0.2 \%$ TFA containing both $0.3 \mathrm{mg}$ EDTA dissolved in $0.1 \mathrm{ml} 5 \%$ glucose and $10 \mu \mathrm{g}$ Stsp dissolved in $10 \mu \mathrm{PEG}$ was injected into the C18 column. Eluted components were detected at (C) $292 \mathrm{~nm}$ and (D) $215 \mathrm{~nm}$ by UV absorption. 
Since EDTA can be substituted for heparin in the preparation of plasma, we investigated EDTA chromatography in the HPLC system. The $10.5 \mathrm{mg}$ EDTA in a coated blood collection tube was dissolved in $3.5 \mathrm{ml}$ of $5 \%$ glucose, and $100 \mu \mathrm{l}$ of this solution ( $0.3 \mathrm{mg}$ EDTA) was added to $1 \mathrm{ml}$ of aqueous $0.2 \%$ TFA containing $10 \mu \mathrm{g}$ Stsp dissolved in PEG. When this sample was subjected to HPLC, three peaks were detected at $292 \mathrm{~nm}$ eluting at 18, 23, and $26 \mathrm{~min}$ (Fig. 8C). These peaks were identified as EDTA, glucose, and Stsp, respectively. EDTA detection was greater at $215 \mathrm{~nm}$, but glucose was not detected at this wavelength (Fig. 8D). An unknown substance eluting ahead of Stsp at 25 min was detected at $215 \mathrm{~nm}$, but this substance was invisible at $292 \mathrm{~nm}$ and did not interfere with Stsp analysis. It was concluded that the collection of blood and preparation of plasma could be accomplished using EDTA without interference of EDTA with Stsp analysis.

Quantification of Staurosporine in Plasma Samples: From the above experiments, we designed a protocol for Stsp analysis. The details of this protocol are described in the Methods section. To determine if the method gave quantitative results, we spiked plasma samples collected in EDTA with known quantities of Stsp dissolved in PEG. The plasma proteins were precipitated with acetone, the protein pellets were washed twice with acetone, and the combined acetone solutions were diluted $2: 1$ with aqueous $0.2 \%$ TFA. This 6-ml sample was pumped thorough the $\mu$ Bondapak C18 column, followed by $5 \mathrm{ml}$ of aqueous $0.2 \%$ TFA to rinse out the sample tube, pump, and pump lines. Following this loading procedure, we continued pumping aqueous $0.2 \%$ TFA through the column to flush out the acetone until the absorbance of $292 \mathrm{~nm}$ was less than 1 . The Stsp was then eluted with the linear acetonitrile gradient. For example, HPLC of a plasma sample containing $2 \mu \mathrm{g}$ Stsp is illustrated in Fig. 9A. The Stsp peak area was determined by computer analysis (Fig. 9B). A calibration curve was constructed from samples containing various amounts of Stsp (Fig. 9C). The calibration is linear with respect to micrograms Stsp loaded on the column and the correlation coefficient $\left(r^{2}\right)$ of this calibration curve is 0.999 . The limit of detection is $0.1 \mu \mathrm{g}$ Stsp.

Stability of Staurosporine in Frozen Samples: It was anticipated that our experiments would require the storage of frozen plasma samples containing various amounts of Stsp before analyses could be performed. To determine if the Stsp was stable under such conditions, we subjected fresh plasma samples containing various amounts of Stsp to analysis and then froze and stored the samples at $-25^{\circ} \mathrm{C}$. At various times thereafter, the samples were thawed and reanalyzed (Fig. 10A). These data indicated that Stsp was stable in frozen plasma and that no change in the Stsp analysis occurred outside its normal $\pm 6 \%$ 

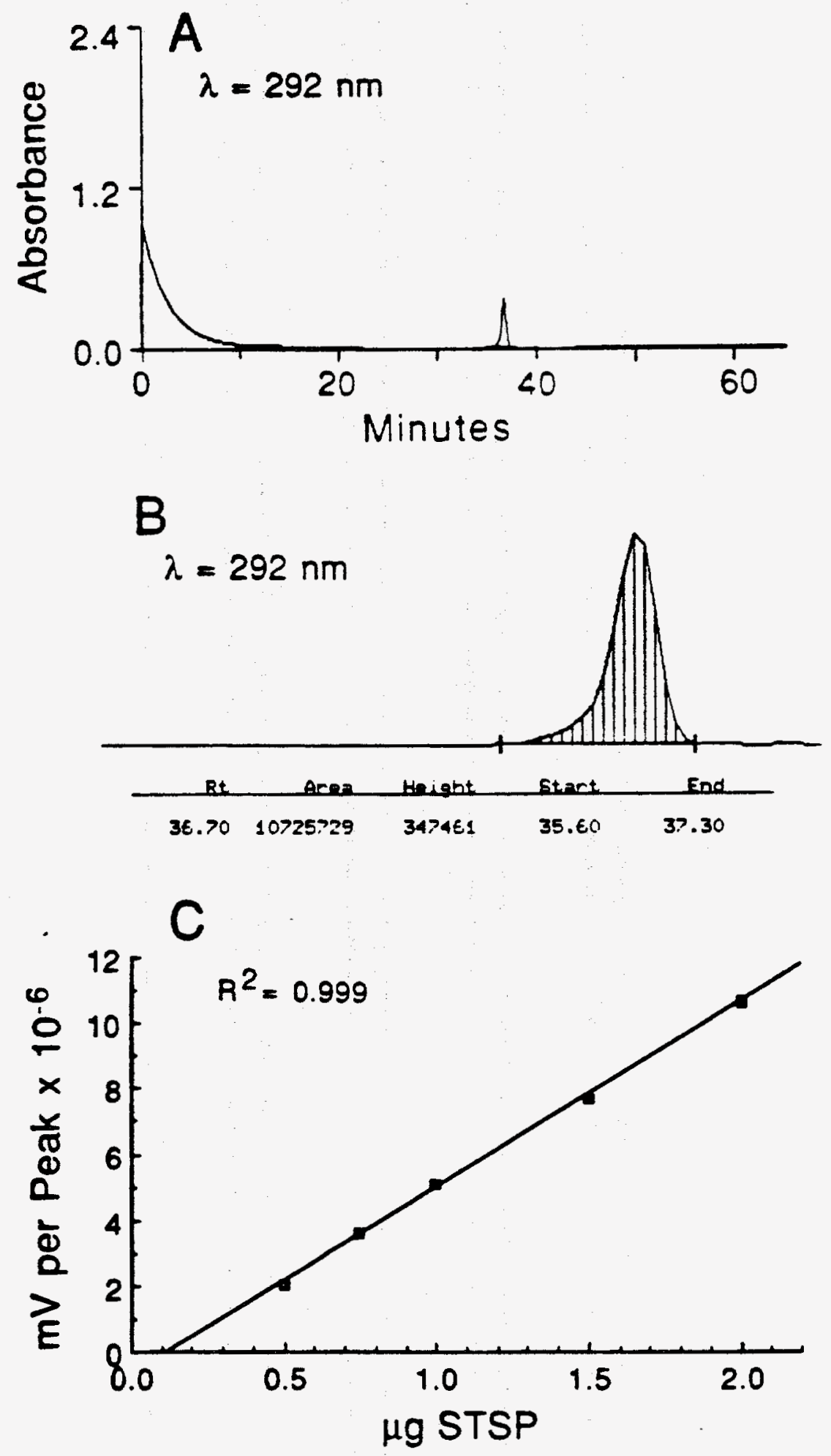

Figure 9. Quantification of staurosporine by HPLC analysis. Plasma obtained from EDTAtreated blood was spiked with various concentrations of Stsp. The proteins of a $100-\mu \mathrm{l}$ plasma sample were precipitated with acetone and the precipitate was washed twice with acetone. The pooled acetone containing the Stsp was diluted $2: 1$ with aqueous $0.2 \%$ TFA and subjected to HPLC. (A) HPLC elution of $2 \mu \mathrm{g}$ Stsp detected by UV absorption at $292 \mathrm{~nm}$. (B) Computer quantification of the Stsp peak eluted at $36.7 \mathrm{~min}$. (C) Calibration curve of the peak area (in accumulated $\mathrm{mV} /$ peak) vs micrograms of Stsp in the plasma sample. 


\section{STSP Stability in Frozen Samples}
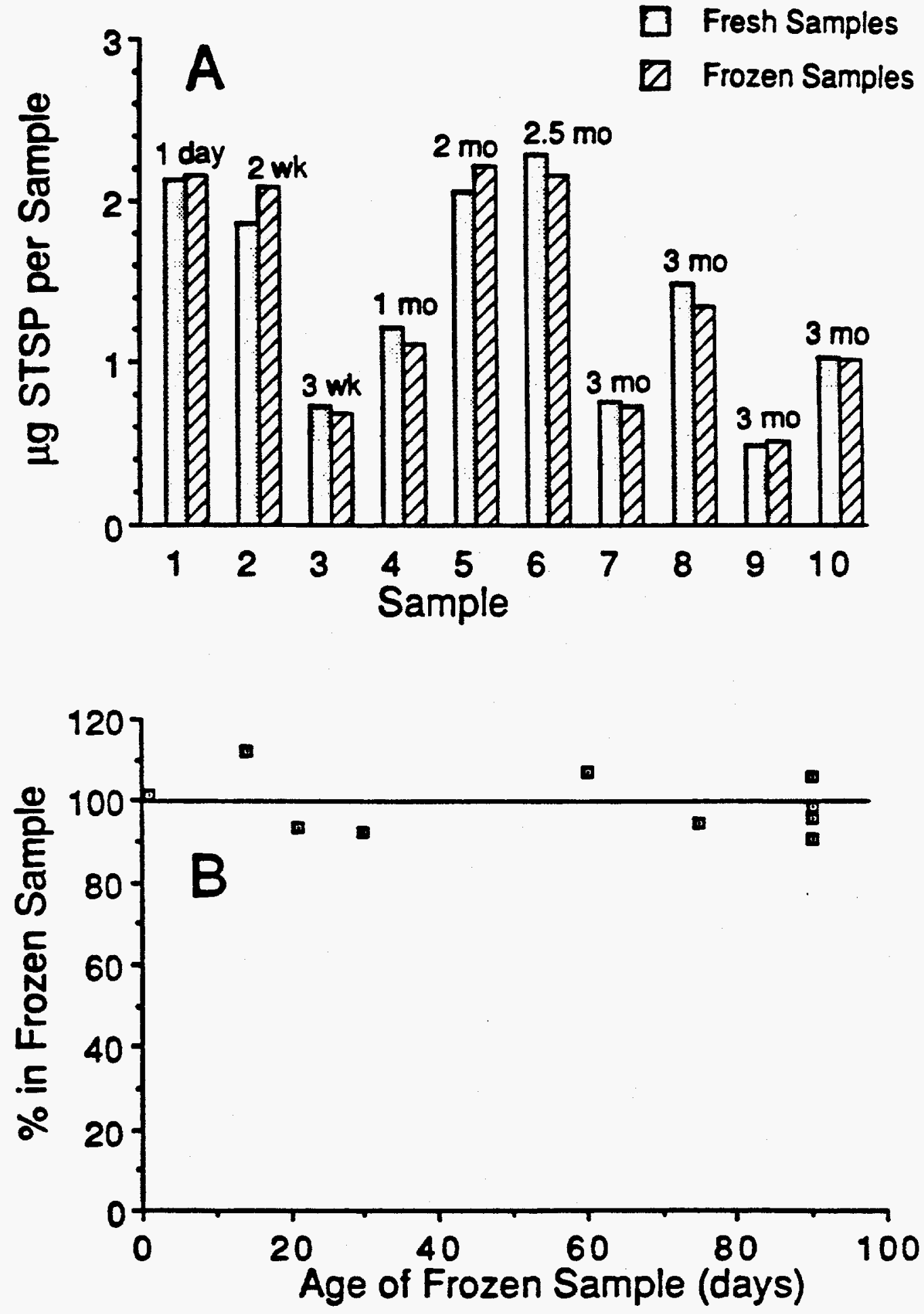

Figure 10. Effect of frozen plasma age on staurosporine analysis. (A) Fresh (unfrozen) plasma samples containing various concentrations of Stsp were subjected to HPLC analysis (solid bars). These samples were then frozen at $-25^{\circ} \mathrm{C}$ for various times ranging from 1 day to 3 months. At the end of the frozen time period, the samples were again subjected to HPLC analysis (crosshatched bars). (B) Analyses of the frozen samples are presented as a percentage of the fresh, unfrozen samples. 
average variance over the course of 3 months in storage (Fig. 10B). This stability makes it possible to collect in vivo samples, prepare plasma immediately, and then freeze the samples for Stsp analysis at a later, more convenient time following the in vivo part of an experiment.

Staurosporine in Plasma of Rats Given Stsp In Vivo: The Stsp assay developed above was used to analyze the level of Stsp in plasma after a single bolus injection of $0.2 \mathrm{mg}$ Stsp dissolved in $0.2 \mathrm{ml}$ of PEG was administered into the jugular vein of a rat. If this amount of Stsp was uniformly distributed throughout the 10 -ml blood volume of a rat and if the Stsp was distributed by passive diffusion throughout the volume of the $\mathrm{RBC}$ as well as the volume of the plasma, the concentration of Stsp would be expected to be $20 \mu \mathrm{g} / \mathrm{ml}$ in the plasma. Acetone extraction of a $0.1-\mathrm{ml}$ aliquot of this plasma would result in a $2-\mu \mathrm{g}$ Stsp load for HPLC analysis. A plasma sample spiked with $2 \mu \mathrm{g}$ Stsp simulating this initial (time zero) condition is shown in Fig. 11A. If the Stsp did not penetrate the red blood cells and was thus confined to the 5-ml fluid plasma compartment, the concentration of Stsp in the plasma would be expected to be $40 \mu \mathrm{g} / \mathrm{ml}$, resulting in an HPLC load of $4 \mu \mathrm{g}$ Stsp (twice that shown in Fig. 11A). From these considerations, the analysis of Stsp in the in vivo samples of this experiment was expected to be within the operational range of the assay.

However, when blood samples were collected by cardiac puncture, $5 \mathrm{~min}$ or $15 \mathrm{~min}$ after injection of Stsp, no Stsp could detected in the plasma (Fig. 11B and 11C, respectively). Thus, the levels of Stsp in the plasma were $<0.1 \mu \mathrm{g}$ per $0.1 \mathrm{ml}$ sample, which is the detection limit of this assay (see calibration curve, Fig. 9C). This reduction of plasma Stsp from $40 \mu \mathrm{g} / \mathrm{ml}$ to $<1 \mu \mathrm{g} / \mathrm{ml}$ in less than $5 \mathrm{~min}$ indicated that the Stsp was being either rapidly destroyed or transferred from the plasma compartment to some other compartment in vivo.

Uptake of Staurosporine by Red Blood Cells: If Stsp is being removed from the plasma and sequestered in some other compartment in vivo, the most likely candidate for this sequestration is the red blood cells that are suspended in the plasma. To determine if this is happening, we spiked $1 \mathrm{ml}$ of whole rat blood with $20 \mu \mathrm{g} \mathrm{Stsp}$ and incubated it at $37^{\circ} \mathrm{C}$ for $15 \mathrm{~min}$. The $\mathrm{RBC}$ were then separated from the plasma by centrifugation and $100-\mu \mathrm{l}$ samples of both RBC and plasma were extracted with acetone and the acetone was diluted and subjected to HPLC analysis as described above. The analysis of blood from five different rats indicated that Stsp was removed from the plasma and sequestered in RBC in an RBC:plasma ratio of 2.1:1 (Table 1). 

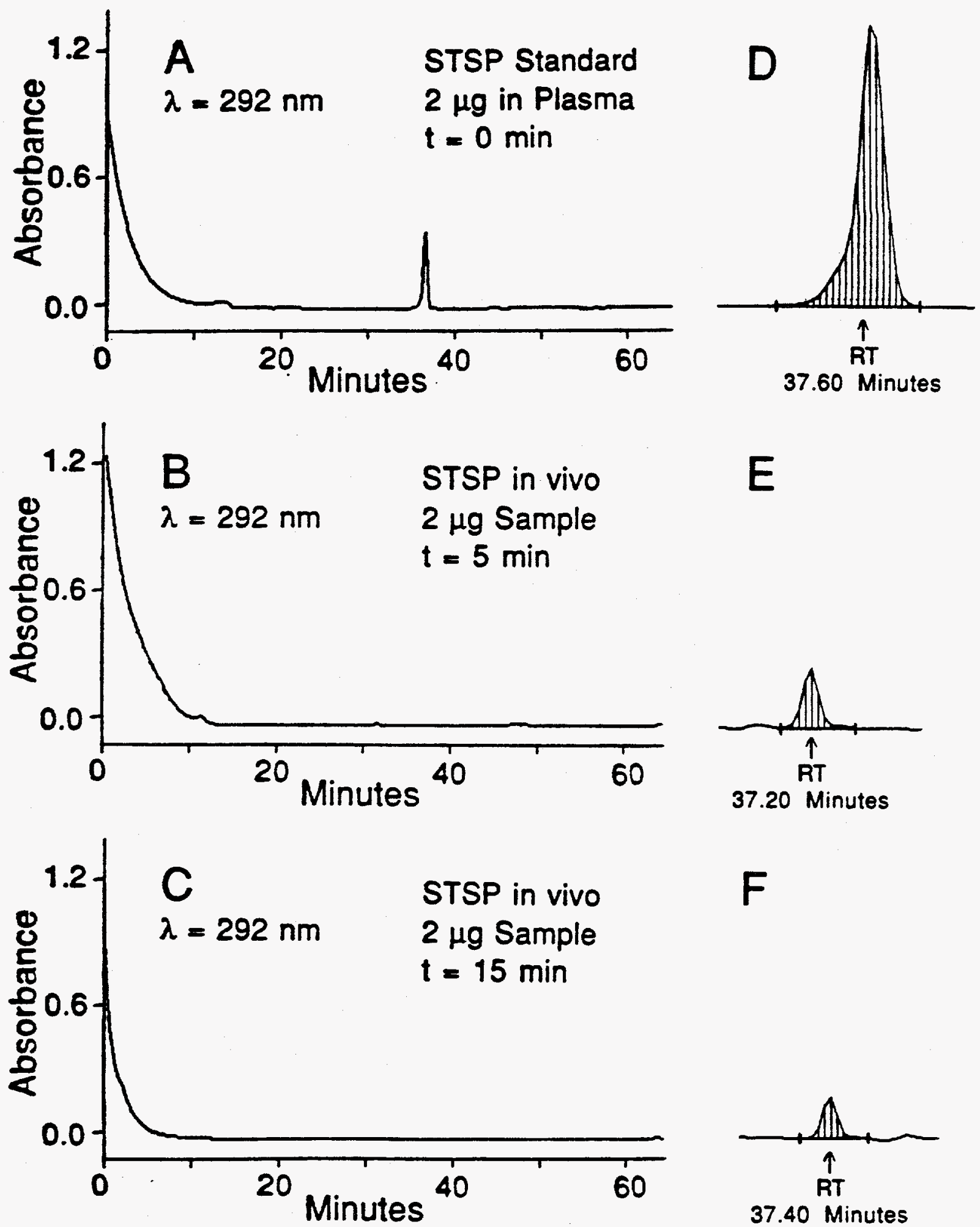

Figure 11. HPLC analysis of staurosporine in the plasma of rats injected intravenously with staurosporine. (A) Analysis of plasma sample spiked in vitro with $2 \mu \mathrm{g}$ Stsp.

(B) Analysis of a $0.1-\mathrm{ml}$ plasma sample withdrawn from a rat $5 \mathrm{~min}$ after administering a $200-\mu \mathrm{g}$ bolus injection of Stsp. (C) Analysis of a $0.1-\mathrm{ml}$ plasma sample withdrawn from a rat 15 min after a $200-\mu \mathrm{g}$ bolus injection of Stsp was administered. (D) "Scanner" amplified Stsp peak seen at $37.6 \mathrm{~min}$ in Fig. 11 A. (E) "Scanner" amplified Stsp peak undetected at $37.2 \mathrm{~min}$ in Fig. 11B. (F) "Scanner" amplified Stsp peak undetected at 37.4 min in Fig. 11C. 
Table 1. Uptake of Stsp in Red Blood Cells

\begin{tabular}{|c|c|c|c|c|c|}
\hline \multirow{2}{*}{$\begin{array}{c}\text { Rat } \\
\text { Number }\end{array}$} & \multicolumn{2}{|c|}{$\mathrm{RBC}$} & \multicolumn{2}{|c|}{ Plasma } & \multirow[b]{2}{*}{$\begin{array}{c}\text { RBC:plasma } \\
\text { ratio } \\
\end{array}$} \\
\hline & $\mu \mathrm{g} / 0.1 \mathrm{ml}$ & $\mu \mathrm{g} / 0.5 \mathrm{ml}$ & $\mu \mathrm{g} / 0.1 \mathrm{ml}$ & $\mu \mathrm{g} / 0.5 \mathrm{ml}$ & \\
\hline 1 & 2.19 & 10.95 & 0.86 & 4.30 & $2.5: 1$ \\
\hline 2 & 1.50 & 7.50 & 1.20 & 6.00 & $1.3: 1$ \\
\hline 3 & 2.60 & 13.00 & 1.04 & 5.20 & $2.5: 1$ \\
\hline 4 & 2.18 & 10.90 & 1.03 & 5.15 & $2.1: 1$ \\
\hline 5 & 2.05 & 10.25 & 1.04 & 5.20 & $2.0: 1$ \\
\hline Average & & & & & $2.1: 1$ \\
\hline
\end{tabular}

There was concern that acetone might not efficiently extract Stsp from intact RBC. However, when the RBC were lysed by two freeze-thaw cycles followed by sonication prior to acetone extraction, HPLC analysis still indicated that Stsp was removed from the plasma and sequestered in $\mathrm{RBC}$ in a ratio of 2.1:1 (Table 2). These experiments suggested that the $\mathrm{RBC}$ are a sink for Stsp administered in vivo.

Table 2. Effect of RBC Lysis on Stsp Extraction

\begin{tabular}{|c|c|c|c|c|c|}
\hline \multirow{2}{*}{$\begin{array}{c}\text { Rat } \\
\text { Number }\end{array}$} & \multicolumn{2}{|c|}{$\mathrm{RBC}$} & \multicolumn{2}{|c|}{ Plasma } & \multirow[b]{2}{*}{$\begin{array}{c}\text { RBC:plasma } \\
\text { ratio }\end{array}$} \\
\hline & $\mu \mathrm{g} / 0.1 \mathrm{ml}$ & $\mu \mathrm{g} / 0.5 \mathrm{ml}$ & $\mu \mathrm{g} / 0.1 \mathrm{ml}$ & $\mu \mathrm{g} / 0.5 \mathrm{ml}$ & \\
\hline 1 & 2.57 & 12.85 & 1.06 & 5.30 & $2.4: 1$ \\
\hline 2 & 2.15 & 10.75 & 1.03 & 5.15 & $2.1: 1$ \\
\hline 3 & 2.59 & 12.95 & 1.17 & 5.85 & $2.2: 1$ \\
\hline 4 & 1.99 & 9.95 & 1.04 & 5.20 & $1.9: 1$ \\
\hline 5 & 2.06 & 10.30 & 1.04 & 5.20 & $2.0: 1$ \\
\hline Average & & & & & $2.1: 1$ \\
\hline
\end{tabular}

To determine the kinetics of Stsp uptake by RBC, we incubated $500 \mu$ l of whole blood with $10 \mu \mathrm{g}$ Stsp for various periods of time. Following incubation, the RBC were removed from the plasma by centrifugation. The shortest centrifugation time required to effectively sediment the RBC was 2 min (insert in Fig. 12A). Thus, our shortest incubation time was the 2-min exposure of RBC to Stsp during this centrifugation step. 

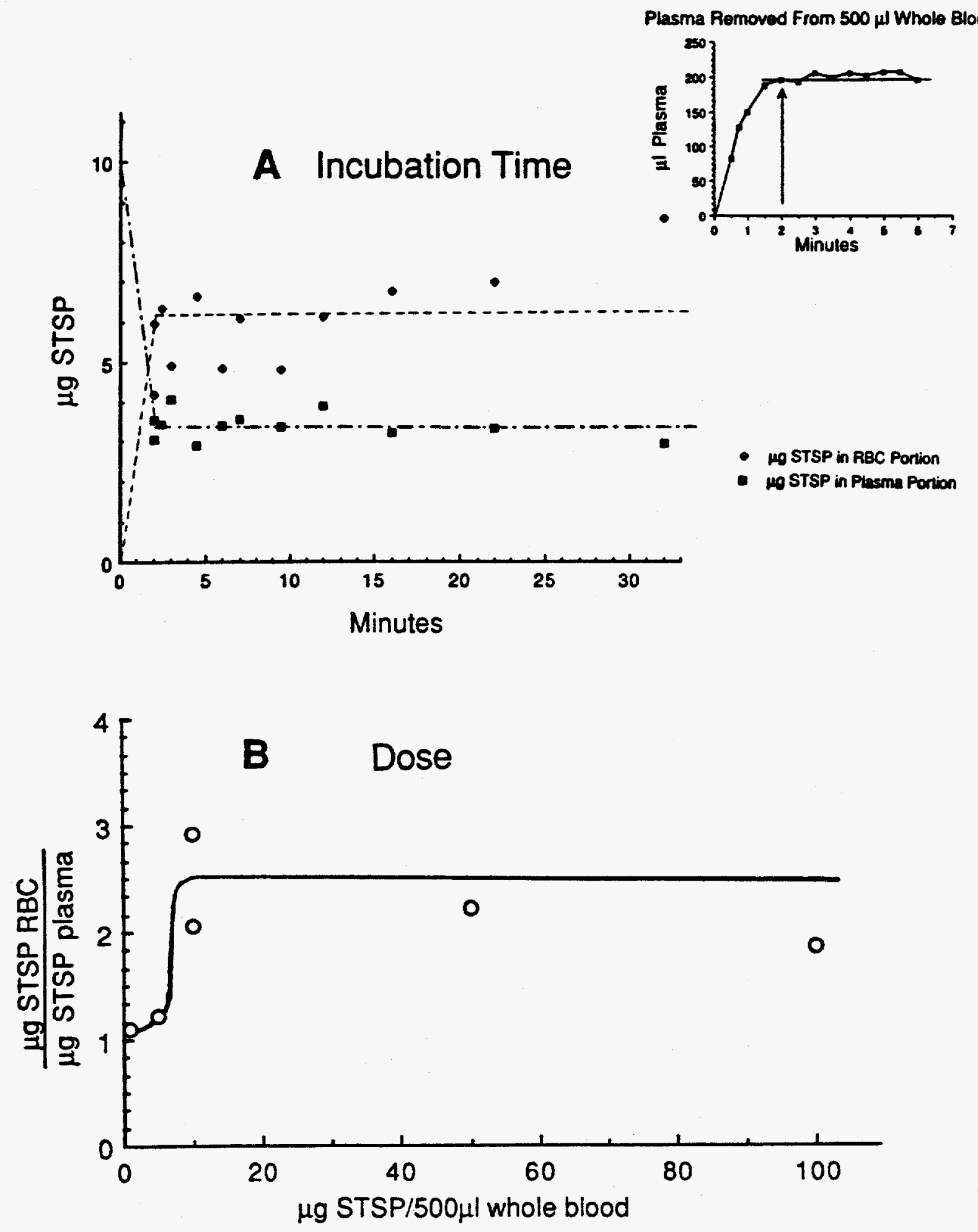

Figure 12. Kinetics and dose dependency of staurosporine uptake by red blood cells. (A) Kinetics of Stsp uptake: $500 \mu \mathrm{l}$ whole blood was incubated with $10 \mu \mathrm{g}$ Stsp at $37^{\circ} \mathrm{C}$ for various periods of time. Following this, the blood was centrifuged for $2 \mathrm{~min}$, which is the shortest time required for sedimentation of RBC (figure insert, upper right). The supernatant plasma and RBC pellet were separated and each was analyzed for Stsp by HPLC. (B) Dose dependency of Stsp uptake by RBC: $500 \mu l$ whole blood was incubated at $37^{\circ} \mathrm{C}$ for $15 \mathrm{~min}$ with various doses of Stsp. Following centrifugation, the plasma and RBC were each analyzed for Stsp by HPLC. 
The plasma was removed from the RBC pellet immediately after centrifugation and the Stsp was measured in both RBC and plasma. These data indicated that the RBC:plasma Stsp distribution reached an equilibrium ratio of $2: 1$ in less than $2 \mathrm{~min}$ (Fig. 12A).

The dose dependency of the RBC:plasma Stsp distribution was measured on similar whole blood samples incubated $15 \mathrm{~min}$ at $37^{\circ} \mathrm{C}$. It was found that a concentration of $10 \mu \mathrm{g}$ Stsp/500 $\mu \mathrm{l}$ whole blood $(20 \mu \mathrm{g} / \mathrm{ml})$ was required to produce the maximum $2: 1$ RBC:plasma distribution of Stsp. Below this concentration, the distribution was reduced to 1:1 (Fig. 12B). These data demonstrated that the in vivo experiment in Fig. 11B was conducted for a sufficient time $(5 \mathrm{~min})$ and at a sufficient dose $(20 \mu \mathrm{g} / \mathrm{ml})$ to facilitate maximum uptake of Stsp by the RBC in vivo.

The 2:1 RBC:plasma distribution of Stsp existed over a 10-fold range (Fig. 12B). This indicates that the Stsp affinity for RBC is weak, resulting in an equilibrium being established between these two blood compartments. If the RBC were the only sink for Stsp in vivo, the $200-\mu \mathrm{g}$ bolus injection given rats in Fig. 11 should have resulted in a 2:1 distribution of Stsp between RBC and plasma, or a concentration of $2.7 \mu \mathrm{g} \mathrm{Stsp} / 100 \mu \mathrm{l}$ $\mathrm{RBC}$ and $1.3 \mu \mathrm{g}$ Stsp/ $100 \mu \mathrm{l}$ plasma, which would be easily detectable by our analytical procedure (Fig. 9C). Since no Stsp was detectable under these conditions (Fig. 11, B and C), it must be concluded that some other compartment in addition to RBC is sequestering the Stsp, perhaps the endothelium of the heart and lungs.

Removal of Staurosporine from Plasma by Red Blood Cells: The 0.2-ml volume of Stsp injected into a rat would be exposed to a constantly changing set of RBC due to turbulence in the vascular system in vivo. To determine how many sets of RBC it would take to reduce the plasma Stsp concentration to nondetectable levels, we exposed plasma containing Stsp to a series of fresh RBC. After each exposure the plasma and RBC were analyzed for Stsp by HPLC. Similarly, RBC containing Stsp were exposed to a series of fresh plasma samples to determine if Stsp would be redistributed from the RBC to the plasma. This experiment and its results are diagrammed in Fig. 13.

In this experiment, $40 \mu \mathrm{g}$ Stsp was added to $2 \mathrm{ml}$ of whole rat blood and incubated for $15 \mathrm{~min}$ at $37^{\circ} \mathrm{C}$. The $\mathrm{RBC}$ and plasma were then separated by centrifugation. At this step, the Stsp was partitioned between the RBC and plasma in a ratio of 1.84:1. When the plasma from this sample was exposed to fresh $\mathrm{RBC}$ containing no Stsp, the Stsp was again partitioned with a RBC:plasma ratio of $2.68: 1$. When the plasma from that sample was exposed a third time to fresh $\mathrm{RBC}$, the Stsp was partitioned with an $\mathrm{RBC}$ :plasma ratio 


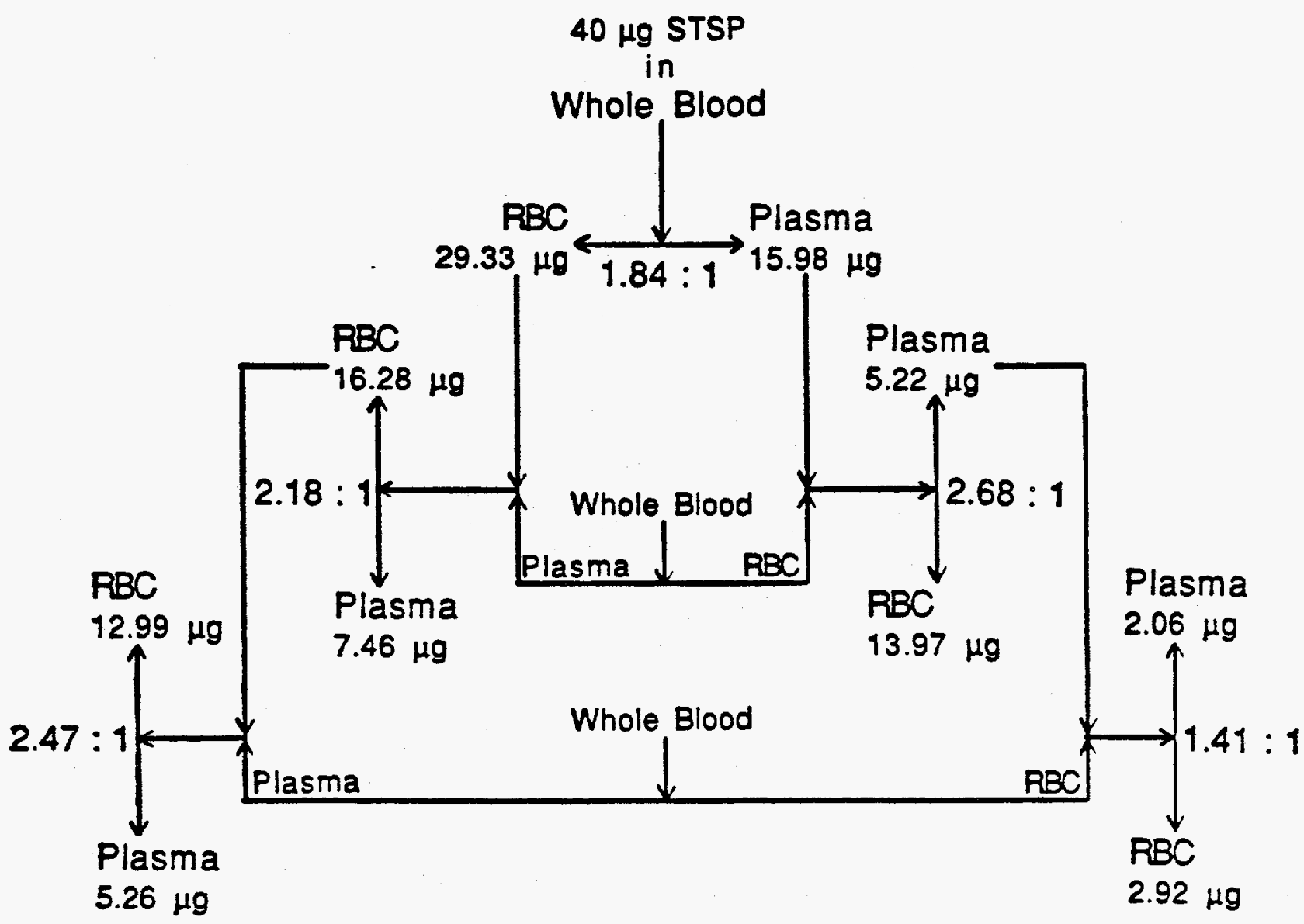

Ratios $=\mu g$ STSP in RBC $: \mu g$ STSP in Plasma

Figure 13. Diagram of an experiment demonstrating the removal of staurosporine from the plasma by red blood cells. Whole rat blood spiked with $40 \mu \mathrm{g}$ Stsp was separated into plasma and RBC. The Stsp-containing plasma was then exposed to Stsp-free RBC and the Stsp-containing RBC were exposed to Stsp-free plasma that was separated from untreated whole blood in the second step. This procedure was repeated in a third step. The Stsp recovered in the plasma and RBC was determined by HPLC analysis of $0.1-\mathrm{ml}$ aliquots at each stage of the experiment and is shown beneath the plasma and RBC. The $\mathrm{RBC}$ :plasma Stsp ratio is shown between the RBC and plasma at each stage of the experiment. 
of 1.41:1. When the concentration of Stsp in the plasma after each exposure was plotted on a semilog scale, it was found that the Stsp was removed from the plasma exponentially with continuous exposure to fresh RBC (Fig. 14A). From this plot, it was also determined that the Stsp in the plasma would be reduced to below-detectable levels in less than five exposures to fresh RBC $(0.1 \mu \mathrm{g}$ Stsp/100 $\mu$ l intercept in Fig. 14).

When the RBC from the initial Stsp-exposed whole blood sample in Fig. 13 were exposed to fresh plasma, part of the Stsp in the RBC was redistributed to the plasma, but the RBC:plasma ratio remained 2.18:1 (Fig. 13). When those RBC were again exposed to fresh plasma, the Stsp was again redistributed to the plasma, but the RBC:plasma ratio remained 2.47:1. When the concentration of Stsp in the RBC after each exposure was plotted on a semilog scale, the RBC concentration of Stsp was rapidly reduced, but at a slower rate than the Stsp concentration in plasma exposed repeatedly to fresh RBC (Fig. 14). Assuming an exponential loss of Stsp from the RBC, extrapolation of the data to the $0.1 \mu \mathrm{g} \mathrm{Stsp} / 100 \mu \mathrm{l}$ intercept indicated that levels of Stsp in RBC would be reduced to below detectable levels in only 11 repeated exposures to fresh plasma in vitro.

These data confirm that the affinity of Stsp for RBC is weak and that in vivo the RBC would be expected to rapidly unload their Stsp to Stsp-free plasma, resulting in a steady state equilibrium being rapidly established between plasma and RBC. These data also reinforce our previous conclusion that, since no Stsp was detectable in vivo (Fig. 11, B and C), there must be some other compartment in addition to the RBC that sequesters the Stsp in the whole animal.

Computer-Amplified Detection of Staurosporine: At this point in the course of these experiments, we discovered that the UV monitor (a Water Model 490 flow detector) could detect a Stsp peak eluting from the column even though the peak was too small to normally be recorded above background. Through the use of a postchromatography computer program called "scanner," as described in the Methods section, the region of the chromatogram where Stsp was expected (36-38 $\mathrm{min}$ ) could be specified to the computer and the scale of the UV absorbance in that region could be greatly expanded. For example, when this expansion operation was performed on the chromatograms in Fig. 11, a Stsp peak could be found (Fig. 11, E and F) even though no Stsp peak was recorded above background during the chromatography (Fig. 11, B and C). A calibration curve was constructed using plasma samples containing 0.01 to $2.0 \mu \mathrm{g}$ Stsp (Fig. 15). The calibration of this computer-amplified detection system was linear with respect to Stsp loaded on the column, and the correlation coefficient $\left(r^{2}\right)$ of the calibration curve was 0.991 . The limit of 


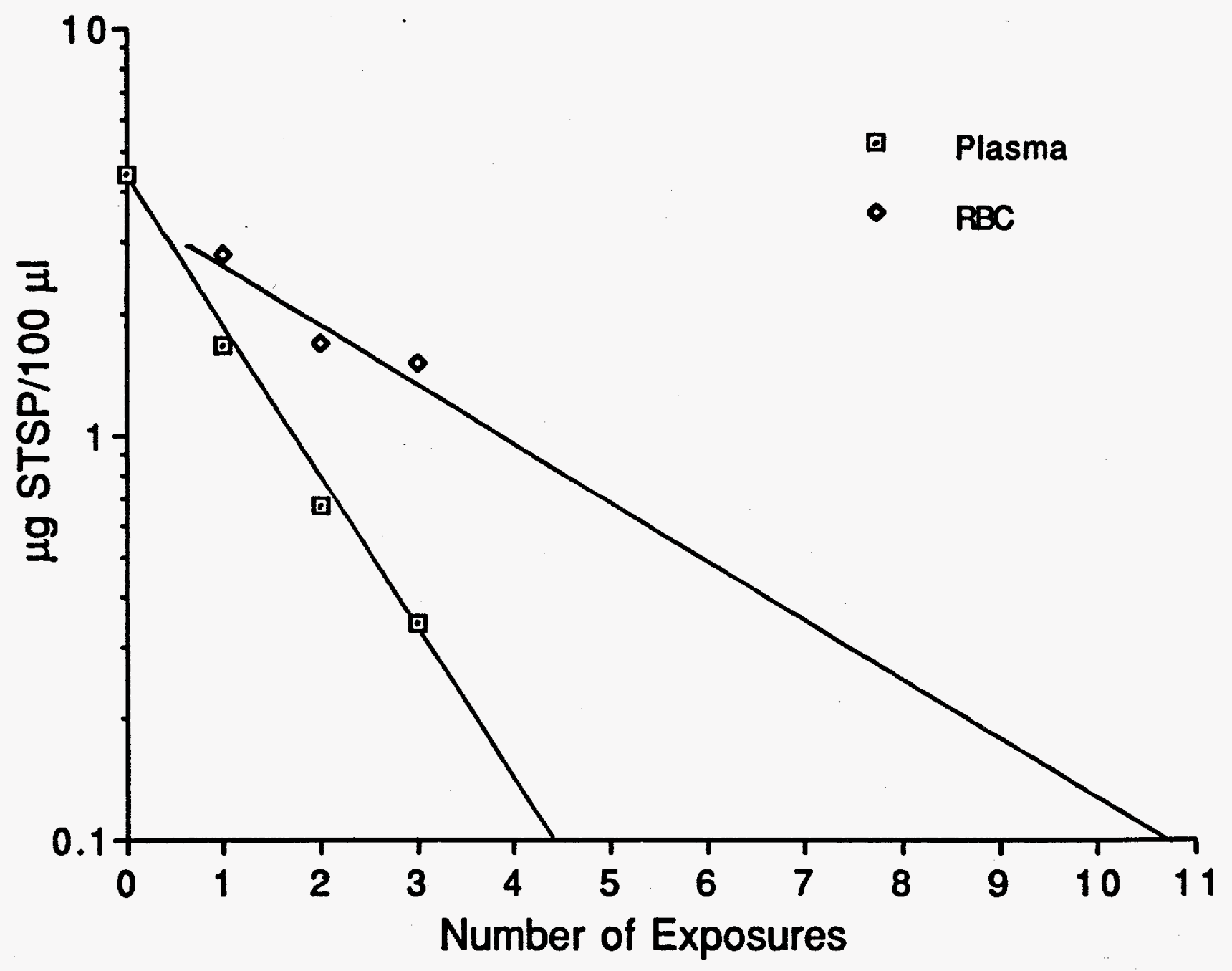

Figure 14. Removal of staurosporine from plasma and RBC by repeated exposures to plasma and red blood cells containing no Stsp. The amounts of Stsp in plasma ( $(\boldsymbol{G})$ and RBC $(\diamond)$ were plotted on a semilog plot after each exposure to untreated RBC and plasma, respectively (see the data in Fig. 13). When these data were extrapolated to $0.1 \mu \mathrm{g} \mathrm{Stsp} / 100 \mu \mathrm{l}$ plasma (the limit of Stsp detection by the HPLC assay) the intercept with the abscissa indicated that $<5$ exposures of plasma to $\mathrm{RBC}$ were required to reduce plasma Stsp to a nondetectable level and $<11$ exposures of RBC to plasma were required to reduce RBC Stsp to a nondetectable level. 


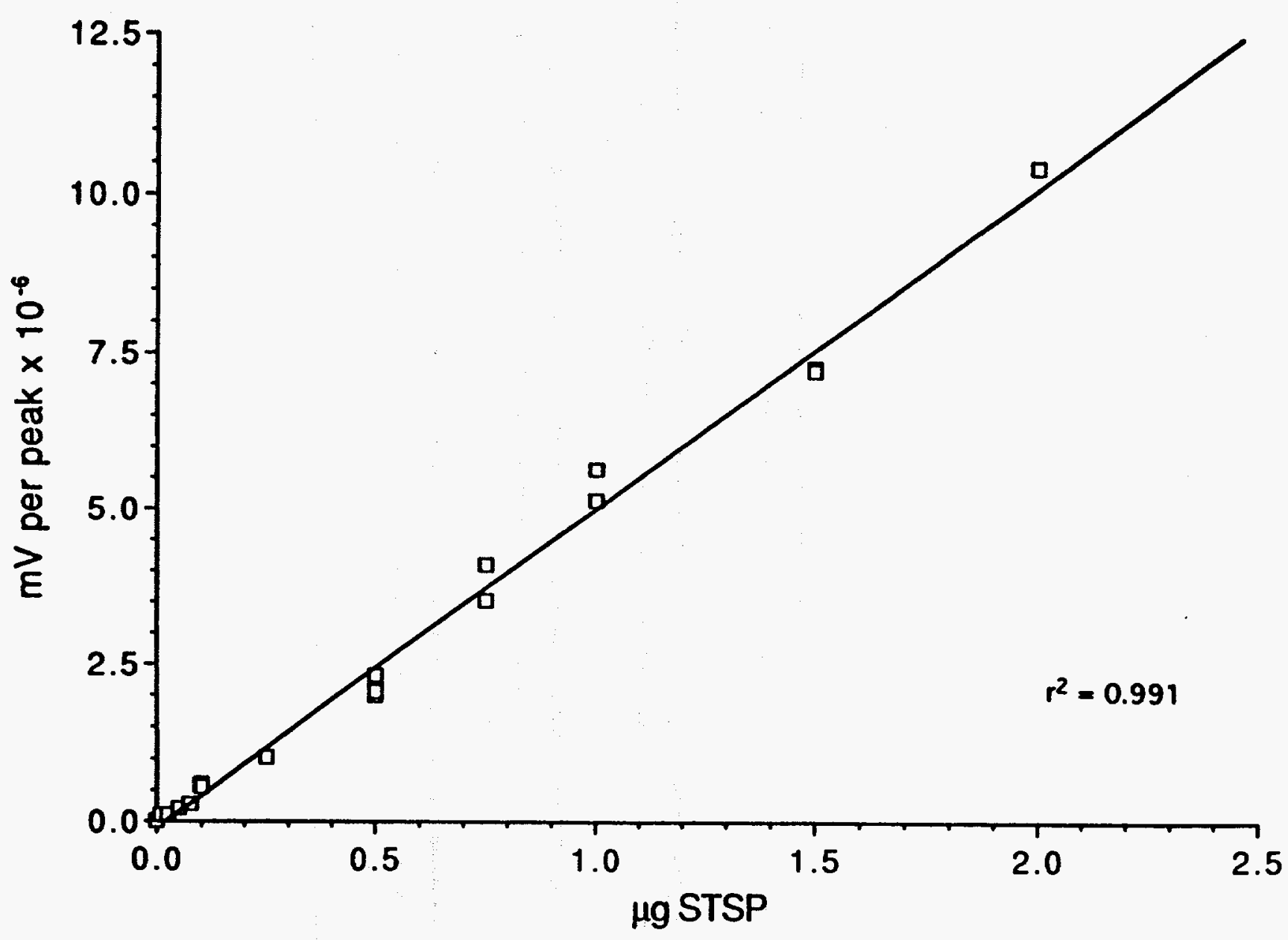

Figure 15. Calibration curve for nanogram quantities of staurosporine in plasma. Plasma samples containing 10-2000 ng Stsp/100 $\mu \mathrm{l}$ were extracted with acetone and the extract was subjected to HPLC. Following the chromatography, the scale of the UV absorbance at $292 \mathrm{~nm}$ in the 35-38 min region of the chromatogram was expanded until the Stsp peak was visible using the "scanner" computer program. The area under the peak was then quantified as the accumulated $\mathrm{mV} /$ peak and plotted vs nanograms of Stsp in the $100-\mu 1$ plasma sample to use as a calibration curve for blood Stsp analysis. The least squares linear fit of the data had a correlation coefficient $\left(\mathrm{r}^{2}\right)$ of 0.991 . 
detection was $20 \mathrm{ng}$ loaded on the column. Thus, this method can be used to measure nanogram quantities of Stsp in blood if the volume of the sample is large enough to contain a total load greater than $20 \mathrm{ng}$.

Pharmacokinetics of Staurosporine In Vivo: Using this computer scale-expansion method for measuring low levels of Stsp in blood, we were able to measure the in vivo kinetics of Stsp loss in the blood of rats. To do this, we dissolved Stsp in PEG at a concentration of $1 \mathrm{mg} / \mathrm{ml}$ and diluted it $1: 1$ with $5 \%$ glucose to reduce the viscosity of the solution. This solution was then injected into the jugular vein to administer a bolus dose of $250 \mu \mathrm{g}$ Stsp. Blood samples were then taken by cardiac puncture from different rats at different times ranging from 5 to $240 \mathrm{~min}$ after injection. A blood sample was also taken from a rat injected with the same solution containing no Stsp to use as a baseline control.

The blood was fractionated into plasma and RBC and both fractions were subjected to HPLC analysis. The Stsp was quantified by postchromatography measurements of the computer-amplified peaks (Fig. 16, A and B). A semilog plot of these data was linear, indicating that Stsp disappeared from both plasma and RBC with first-order kinetics (Fig. 17, A and B). From the least squares fit of those data it was found that, in vivo, the Stsp in plasma had a half-life of $51.6 \mathrm{~min}$ and the Stsp in RBC had a half-life of $75.3 \mathrm{~min}$.

The range in which Stsp has been found to arrest normal cells in G1 and not arrest the proliferation of tumor cells is $1-10 \mathrm{ng} / \mathrm{ml} .{ }^{13}$ Extrapolation of the data in Fig. 17 to $1 \mathrm{ng}$ $\mathrm{Stsp} / \mathrm{ml}$ indicated that Stsp in plasma was in the $1-10 \mathrm{ng} / \mathrm{ml}$ range for only $2.7 \mathrm{~h}$ and was in this range in RBC for only $4.2 \mathrm{~h}$. From these data it is concluded that bolus injections of Stsp alone are not likely to accomplish the arrest of normal cells in G1 in vivo for the following reasons: 1) the initial high concentrations of Stsp in the plasma (Fig. 17A) and in cells (Fig. 17B) will arrest cell-cycle traverse in all phases of the cell cycle in both normal and tumor cells, and 2) the concentration of Stsp in the effective range of $1-10 \mathrm{ng} / \mathrm{ml}$ is of such short duration that normal cells will not be synchronized in $\mathrm{Gl}$ arrest and held there long enough to protect them from the toxic effects of chemotherapeutic drugs. This explains why G1 arrest could not be detected in the bone marrow of rats following Stsp injections. ${ }^{14}$

Tissue Adsorption of Staurosporine: The levels of Stsp in the blood at the earliest time measured in vivo ( $5 \mathrm{~min}$ in Fig. 17) was $200 \mathrm{ng} / \mathrm{ml}$ for plasma and $150 \mathrm{ng} / \mathrm{ml}$ for RBC. Assuming a rat contains $5 \mathrm{ml}$ plasma and $5 \mathrm{ml} \mathrm{RBC}$, only $1,750 \mathrm{ng}$ of the initial $250,000 \mathrm{ng}$ injected $(0.7 \%)$ was found in the circulating blood $5 \mathrm{~min}$ after injection 

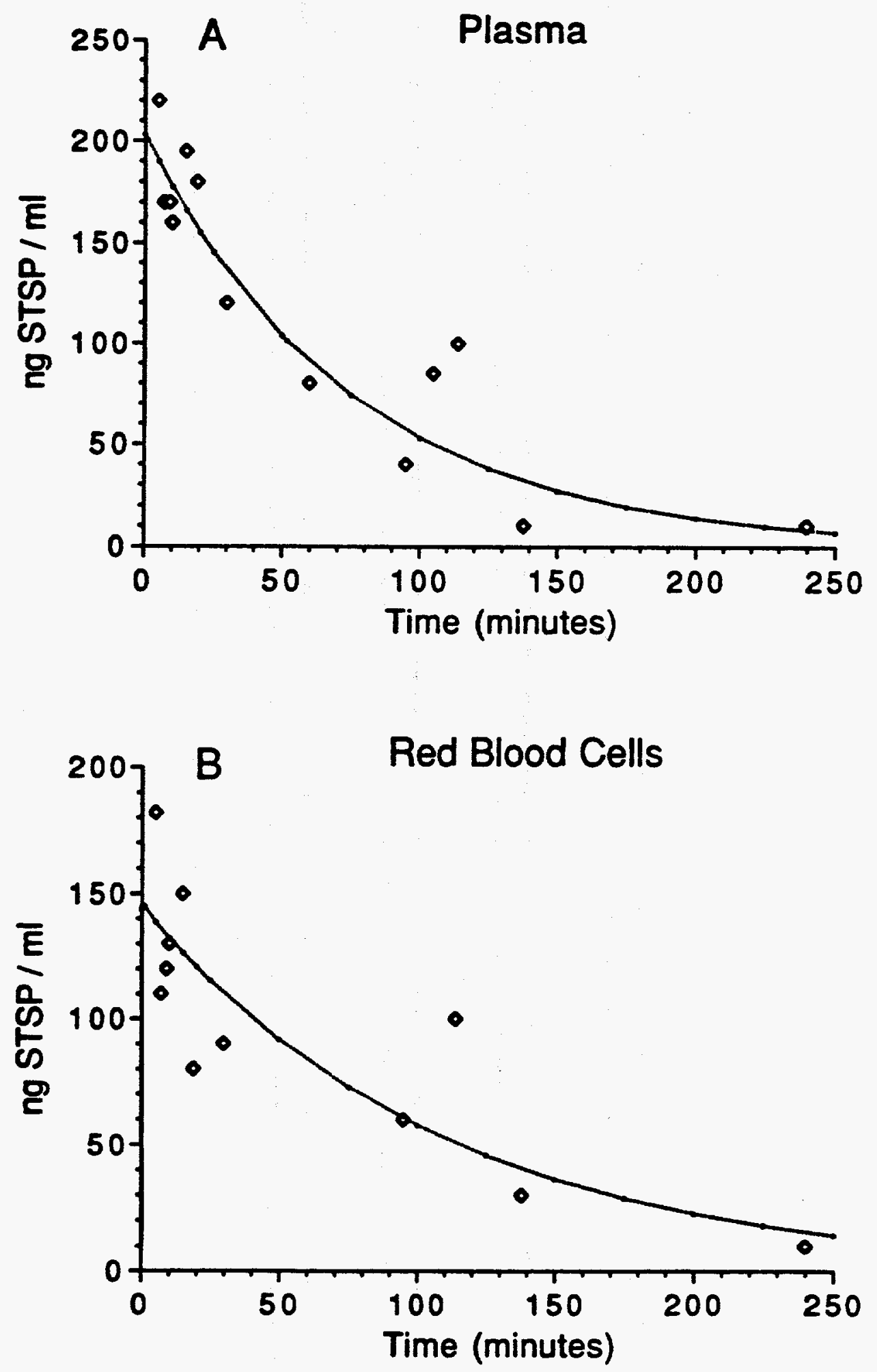

Figure 16. Blood staurosporine levels following injections of a bolus dose of $250 \mu \mathrm{g}$ Stsp into the jugular veins of rats. (A) Plasma Stsp levels. (B) Red blood cell Stsp levels. 

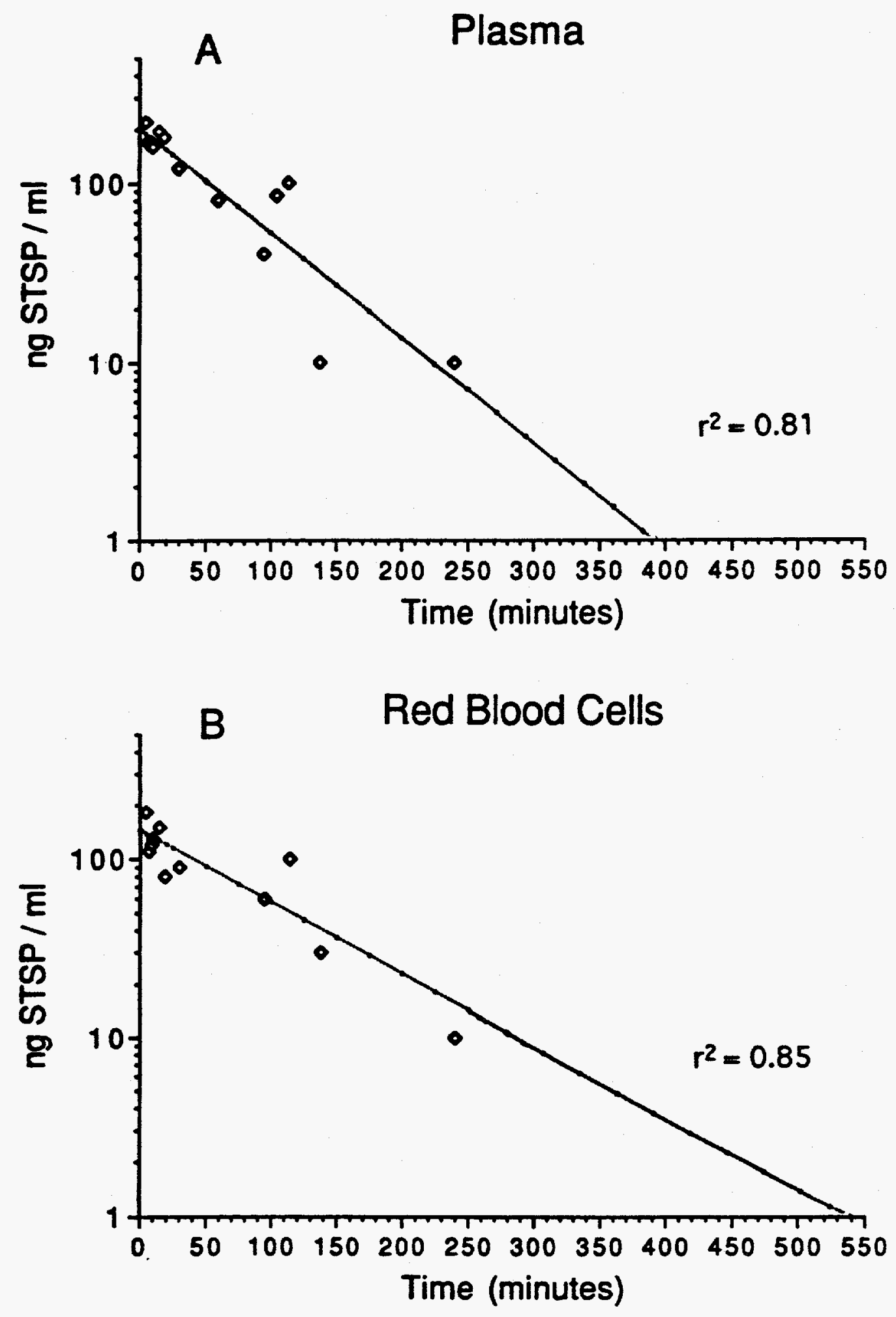

Figure 17. Pharmacokinetics of a $250-\mu \mathrm{g}$ bolus injection of staurosporine in rats. Semilog plots of the data in Fig. 16 were linear, indicating that the kinetics of Stsp lost from both plasma (A) and red blood cells (B) was first order. The least squares fit of the data had a correlation coefficients $\left(\mathrm{r}^{2}\right)$ of 0.81 for plasma and 0.85 for red blood cells. Extrapolation of the data indicated that it took $395 \mathrm{~min}$ to reduce plasma Stsp to $1 \mathrm{ng} / \mathrm{ml}$ and $540 \mathrm{~min}$ to reduce red blood cell Stsp to the same level. 
(Fig. 17). This means that over $99 \%$ of the Stsp is rapidly adsorbed by the tissues of the body.

To measure this directly, we injected $100 \mu \mathrm{g}$ Stsp into rats through a catheter into the superior vena cava leading to the heat. Just before injection a needle fitted with a withdrawal syringe was inserted into the abdominal aorta and tied off so that no blood could flow past it. The Stsp was immediately injected and blood was collected immediately as fast as the heart could pump it through the heart and lungs. Five 1-ml samples of blood were collected in sequence using vacuum vials, the collection taking approximately $10 \mathrm{sec}$ to collect each of the first three samples, $20 \mathrm{sec}$ for the fourth, and $30 \mathrm{sec}$ for the fifth. With this surgical procedure, the Stsp made only one pass through the heart and lungs and was exposed to no other tissues. The blood samples were immediately centrifuged to separate the plasma and $\mathrm{RBC}$, both of which were then frozen.

Analysis of these samples indicated that the heart and lungs adsorbed almost all the Stsp from the blood stream the first time it passed through them (Fig. 18). The total Stsp recovered from rat \#1 was $2,455 \mathrm{ng}$ in $5.3 \mathrm{ml}$ and that recovered from rat \#2 was $1,192 \mathrm{ng}$ in $5.8 \mathrm{ml}$. This amounted to a recovery of $1.2 \%-2.5 \%$ of that injected. These data confirmed the conclusions drawn from Fig. 17 that the body tissues adsorbed most of the Stsp. Furthermore, it demonstrated that this process is extremely fast, occurring within seconds after injection.

Another conclusion drawn from this experiment is that the plasma levels from a $100-\mu \mathrm{g}$ Stsp injection can vary in individual rats from 100 to $400 \mathrm{ng} / \mathrm{ml}$ after one pass through the heart and lungs, a variability confirmed in another experiment (Fig. 19C). This individual variability may account for the variability of the data points in the pharmacokinetic data shown in Fig. 17.

As the blood left the heart and lungs the first time after injection, the Stsp levels in the RBC fluctuated somewhat probably due to the dynamics of the tissue adsorption, RBC adsorption, and blood flow rate (Fig. 18). However, it appears that the level of Stsp in the $\mathrm{RBC}$ was quickly moving to a concentration lower than that seen in the plasma (Fig. 18). This reduced level in $\mathrm{RBC}$ compared with the level in plasma was also seen after steady state was achieved 5 minutes later (Fig. 17). In earlier experiments, when Stsp was added to blood in vitro so that no tissue compartment was involved, the $\mathrm{RBC}$ :plasma ratio was observed to be 2:1 at high Stsp concentrations (Fig. 12). However, at concentrations below $20 \mu \mathrm{g} / \mathrm{ml}$ this concentration of Stsp into RBC was reduced in vitro (Fig. 12). The data in 


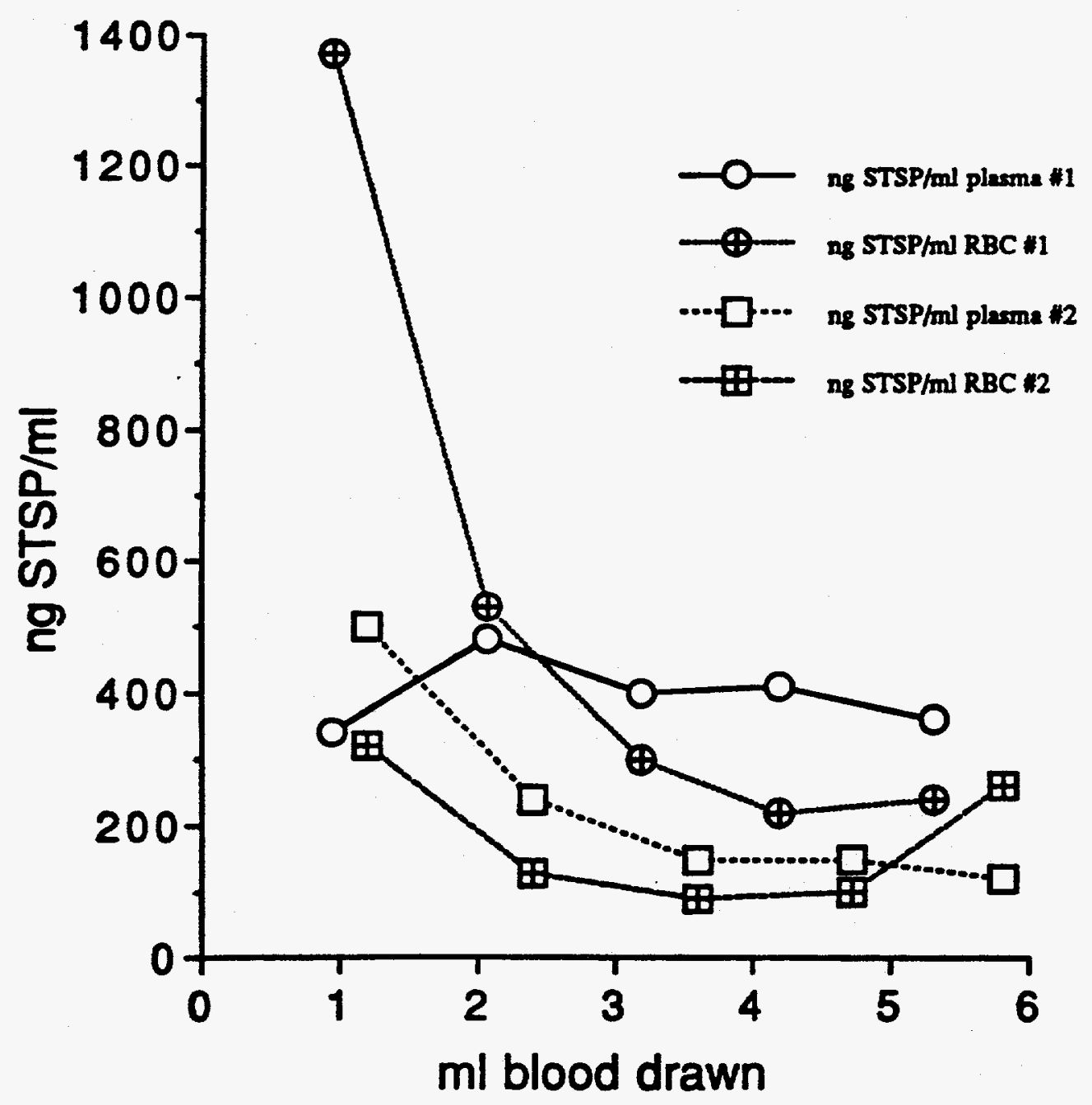

Figure 18. Staurosporine in blood after one pass through the heart and lungs. Two rats were injected with $100 \mu \mathrm{g}$ Stsp into the superior vena cava leading to the heart. Five sequential blood samples were immediately withdrawn from the abdominal aorta, producing samples of blood that had passed through heart and lungs only once. Then $\sim 1-\mathrm{ml}$ blood samples were centrifuged into plasma and RBC and analyzed for Stsp. The concentration of Stsp is plotted vs the total volume of blood collected. 
Fig. 18 indicate that, in vivo, tissue adsorption reduces the Step levels in the circulating blood so much that the RBC:plasma ratio is reduced to less than 1.

To determine if there was a dose dependency on the plasma Stsp concentration leaving the heart and lungs, we injected bolus doses of $500 \mu \mathrm{g}, 250 \mu \mathrm{g}$, and $100 \mu \mathrm{g}$ Stsp into the superior vena cava and blood samples were taken from the abdominal aorta, as described in the previous experiment. Stsp analysis indicated that there was some dose dependency, but the individual animal variability overlapped the dose dependency (Fig. 19, A-C). This suggests that the tissue capacity to adsorb Stsp is greater than any of these levels of Stsp injected. These data also confirm the conclusion reached earlier that there is a wide animal variability of plasma Stsp levels after a single pass through the heart and lungs.

Blood samples were also taken 15 min after a 250- $\mu \mathrm{g}$ Stsp injection (Fig. 19D). By this time the equilibrium between Stsp in the plasma and Stsp in body tissues and RBC had ample time to reach a steady state as indicated by the identical analyses on four successive blood samples. The plasma Stsp level at $15 \mathrm{~min}$ (Fig. 19D) was within the variability range of samples taken after one pass through the heart and lungs (Fig. 19B). This suggests that either the other body tissues are not adsorbing any Stsp or that a Stsp steady state equilibrium is established between plasma, RBC, and body tissues that maintains the plasma levels for the short term. This latter case would seem most logical. For the long term, the plasma Stsp has a half-life of $51.6 \mathrm{~min}$ (Fig. 17), indicating it is either being metabolically destroyed, physiologically eliminated, or irreversibly deposited in some tissue such as fat.

The individual animal variability of plasma Stsp levels is not great enough to be viewed as a problem at this point. Stsp is effective as a normal Gl blocking agent within the range of $1-10 \mathrm{ng} / \mathrm{ml} .{ }^{13}$ The data in Figs. 18 and 19 indicate that the individual variation is less than 10-fold, so it should be possible to determine a dose that would generate plasma Stsp levels within that range.

Extrapolation of the data from the 100- $\mu \mathrm{g}$ Stsp injections (Figs. 18 and 19) which produced plasma levels of $200-700 \mathrm{ng} / \mathrm{ml}$ suggests that $1-\mu \mathrm{g}$ Stsp injections should produce a $2-7 \mathrm{ng} / \mathrm{ml}$ Stsp plasma level which is in the effective range. The short half-life of Stsp in plasma (51.6 min in Fig. 17) indicates that maintaining the plasma Stsp level at $1-10 \mathrm{ng} / \mathrm{ml}$ for the 2- to 3-day period necessary to achieve Gl arrest in vivo will require the infusion of Stsp at some low level following the initial bolus injection. 


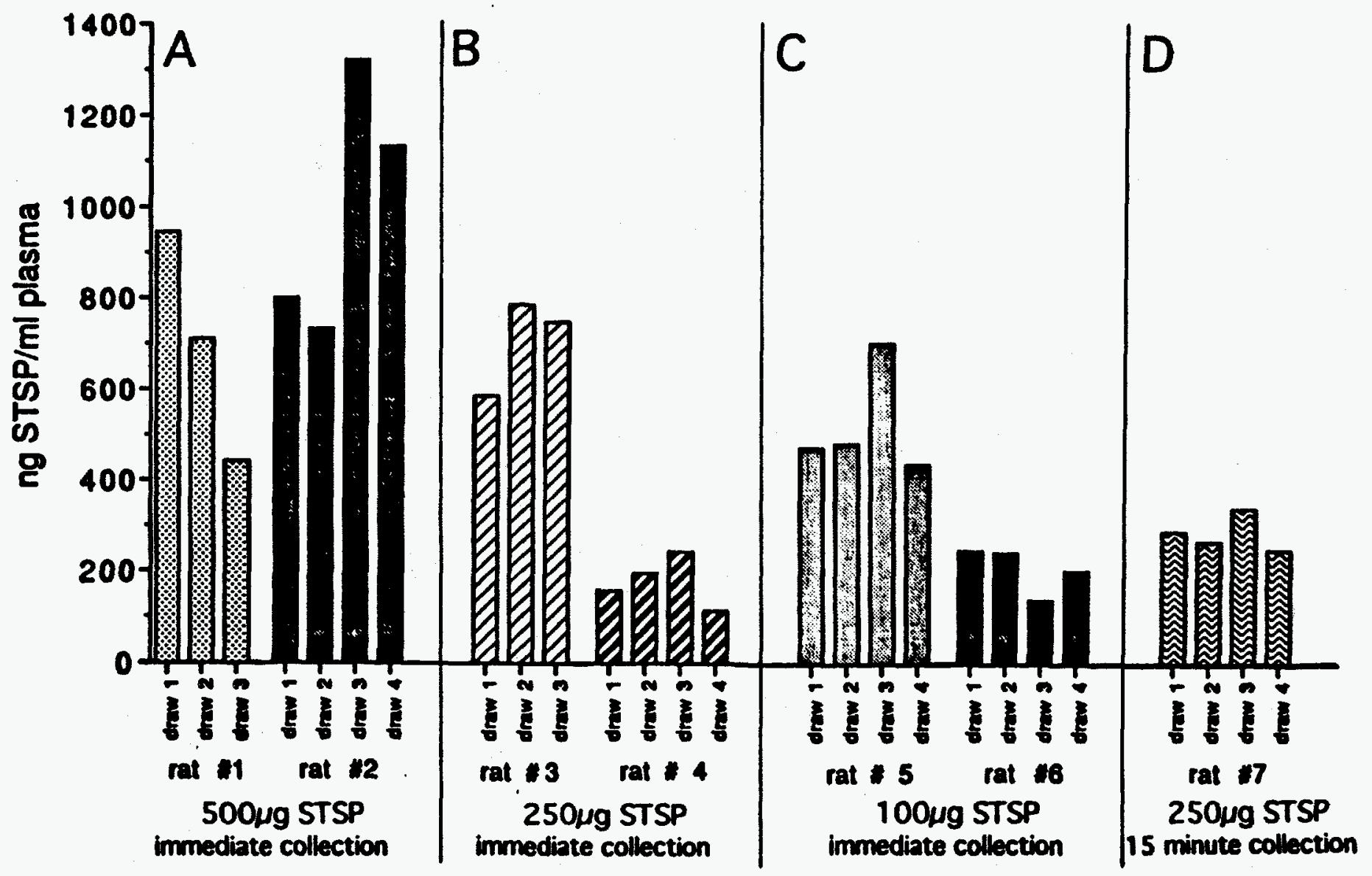

Figure 19. Dose dependency of Stsp concentration in plasma after one pass through heart and lungs. Rats were injected with (A) $500 \mu \mathrm{g}$, (B) $250 \mu \mathrm{g}$, and (C) $100 \mu \mathrm{g}$ Stsp into the superior vena cava leading to the heart. Sequential blood samples were immediately withdrawn from the abdominal aorta producing samples of blood that had passed through heart and lungs only once. Plasma was obtained by centrifugation and analyzed for Stsp. Each bar represents the Stsp concentration in a 1-2 ml sequential blood collection designated by draw number. (D) This rat was injected with $250 \mu \mathrm{g}$ Stsp as the others but sequential blood samples were not collected until $15 \mathrm{~min}$ after injection. 


\section{DISCUSSION}

In this work, we have developed a method for analysis of Stsp in blood samples. The method has the advantage of using common chemical reagents and instruments available in most biochemistry laboratories. The method consists of two processes: the extraction of Stsp with acetone, followed by the purification of the Stsp by HPLC.

In the first process, the treatment of plasma and cells with acetone accomplished two necessary operations in one step. It simultaneously precipitated the proteins out of the sample and extracted the Stsp into a solution free of interfering macromolecular contaminants. In the second process the reversed-phase HPLC also accomplished two necessary operations in one step. It concentrated the Stsp from the very dilute solutions and separated the Stsp from the low molecular weight reagents and blood components. The removal of all these interfering substances enabled us to use the absorbance peak of Stsp at $292 \mathrm{~nm}$ to detect and quantify the drug using a common variable-wavelength flow spectrophotometer.

While the solubility of Stsp in acetone facilitated its extraction from plasma and cells, this solubility was a hindrance during reversed-phase HPLC. The high solubility of Stsp in acetone reduced its interaction with the $\mathrm{C} 18$ column, thus decreasing the recovery of the Stsp on the column. This problem was easily overcome when we diluted the acetone extract 2:1 with water to increase the polarity of the sample solvent. Although this simple step increased the sample volume, the high efficiency of Stsp adsorption on the C18 column under these more polar solvent conditions resulted in the total adsorption of Stsp on the column and in the concentration of Stsp into a sharp origin at the top of the column during the loading process. This resulted in a sharp elution peak which was concentrated enough to be detected by UV adsorption and easily resolved from reagents such as DMSO, EDTA PEG, heparin, and glucose that were used in the procedure.

Heparin, which is commonly used to prevent blood clotting, was found to elute near Stsp during HPLC. This crowding was not a problem for the analysis of Stsp, since heparin could not be detected at the 292-nm wavelength used to quantify Stsp. However, heparin was a problem because it fouled the HPLC column by irreversible adsorption. Thus, we have found that it is best to collect the blood samples in EDTA-treated tubes to prevent clotting. The EDTA elutes far ahead of Stsp and does not interfere with the analysis.

Since our experiments were expected to involved a large number of samples, it was necessary to store blood samples until they could be processed. For this reason, we 
compared the analysis of Stsp in fresh and frozen plasma. We found that samples could be frozen at $-25^{\circ} \mathrm{C}$ for up to 3 months without any quantitative or qualitative changes in analysis.

The analysis of the Stsp peak eluting from the HPLC column at $36 \mathrm{~min}$ was found to be highly accurate when monitored at $292 \mathrm{~nm}$. This was demonstrated by a linear calibration curve having a correlation coefficient $r^{2}=0.999$. Under these conditions the limit of detection was $0.1 \mu \mathrm{g}$ Stsp. While this is not an ultrasensitive method of analysis, we found we could use it in a number of experiments to determine the fate of Stsp in blood.

For example, when Stsp was added to whole blood in vitro, it was found that the RBC took up the Stsp, producing a RBC-to-plasma Stsp ratio of 2.1:1. The kinetics of this uptake was very fast, this ratio being reached in less than two minutes. Dose-dependency studies indicated that this ratio was produced over a wide range of Stsp concentrations. The lower limit of this range was $20 \mu \mathrm{g} \mathrm{Stsp} / \mathrm{ml}$ whole blood, but the same ratio was obtained at $200 \mu \mathrm{g} / \mathrm{ml}$. Below $20 \mu \mathrm{g} / \mathrm{ml}$, the ratio was reduced to 1:1 for RBC:plasma Stsp.

To determine if the RBC permanently sequestered the Stsp, we exposed whole blood to Stsp in vitro and separated the Stsp-loaded plasma and RBC. Then these Stsp-loaded RBC and plasma were repeatedly exposed to fresh plasma and RBC containing no Stsp. From this experiment it was found that the Stsp-loaded RBC redistributed their Stsp to the plasma and the Stsp-loaded plasma was depleted of its Stsp by continuous uptake into the RBC. These data indicated that the RBC do not permanently sequester the Stsp. Rather, in whole blood a steady state equilibrium is established in which the Stsp is distributed between $\mathrm{RBC}$ and plasma in a ratio of $2: 1$.

When Stsp was injected into the bloodstream of rats, however, no Stsp could be detected in the plasma at $5 \mathrm{~min}$ after injection, even though enough Stsp was administered to be easily detectable if it was simply contained in the plasma and RBC. Thus, it must be concluded that in vivo some tissue compartment other than the blood must be adsorbing the Stsp from the plasma and sequestering it. A likely candidate for this Stsp sink would be the endothelium of the heart and lungs.

These experiments suggested that the reason no G1 arrest was observed in the bone marrow of rats injected with Stsp ${ }^{14}$ was that the Stsp never reached its target cells. When the rats were injected with Stsp, the red blood cells immediately took up the Stsp, but then gave it up to tissue cells along the bloodstream, thus reducing the levels of Stsp in the plasma to ineffective levels. 
To determine the injection dose of Stsp that would raise the plasma Stsp dose to an effective level, pharmacokinetic studies on Stsp in vivo were necessary. Such studies required that we develop a more sensitive detection system for Stsp analysis so that nanogram levels of Stsp in the blood could be analyzed. Tissue culture experiments have indicated that an effective level would be expected in the $1-50 \mathrm{ng} / \mathrm{ml}$ range. ${ }^{13}$ Fortunately, at this point in the course of these experiments we found that our UV monitor could detect Stsp peaks too small to be normally recorded above background. The data for these peaks were stored digitally in the computer and could be amplified to a visible level using the scale-expansion operation of the postchromatography analysis program. There was no significant noise in the background of the chromatogram to interfere with analysis of these very small peaks. Using this program, we found that plasma samples from rats injected with Stsp did contain low levels of Stsp too small to be seen normally.

When we ran a standard curve on Stsp at the nanogram level using this postchromatography computer-amplification method, we found that the area of the Stsp peak was linear with respect to Stsp loaded on the column. The standard curve had a correlation coefficient $\left(\mathrm{r}^{2}\right)$ of 0.991 and a detection limit of $20 \mathrm{ng}$, which was sufficient for use in pharmacokinetic experiments in vivo.

In those experiments, $250 \mu \mathrm{g}$ Stsp was injected into the jugular veins of rats, and blood samples were taken by cardiac puncture at various times thereafter. It was found that Stsp disappeared rapidly from both plasma and RBC with first-order kinetics. The plasma Stsp had a half-life of $51.6 \mathrm{~min}$ and the RBC Stsp had a half-life of $75.3 \mathrm{~min}$. From these data it was determined that Stsp in the plasma was in the 1-10 $\mathrm{ng} / \mathrm{ml}$ range in vivo for only 2.7 hours. This was not long enough to create a Gl synchrony in the proliferating bone marrow cells. These data clearly indicate that a single bolus injection of Stsp alone would not accomplish the G1 arrest of normal cells needed in a therapeutic regimen of chemotherapy.

From those data it was also determined that only $0.7 \%$ of the Stsp injected remained in the blood stream after $5 \mathrm{~min}$, which meant that over $99 \%$ of the Stsp was rapidly adsorbed by the tissues of the body. This conclusion was confirmed in studies demonstrating that only one pass of the Stsp through the heart and lungs was necessary for those tissues to adsorb all but $1.2 \%-2.5 \%$ of initial Stsp injected. These experiments also demonstrated that the RBC adsorbed much less of the Stsp in vivo than they did in vitro, producing an in vivo RBC:plasma ratio less than 1, compared with a ratio of 2 observed in vitro. The low in vivo RBC:plasma ratio suggests that the tissue adsorption of Stsp is so fast that the plasma Stsp 
concentration is rapidly lowered below the concentration required for higher RBC:plasma ratios.

These data support an in vivo model of Stsp kinetics in which 99\% of the injected Stsp is rapidly adsorbed by the endothelium cells of the circulatory system, thus greatly reducing the initial plasma levels of Stsp. The remaining $1 \%$ is circulated throughout the body, the Stsp being partitioned between plasma and $\mathrm{RBC}$ with slightly more Stsp in plasma than in the RBC. The circulating levels of Stsp then decays by a first-order kinetic process, in which the plasma Stsp concentration is reduced with a half-life of $52 \mathrm{~min}$. Extrapolation of the data of these experiments suggests that a $1-\mu \mathrm{g}$ Stsp bolus injection should produce an initial Stsp plasma level of 2-7 ng/ml, which is in the effective range for G1 arrest of normal cells. Because of the short half-life of Stsp in vivo, however, it will be necessary to then continuously infuse a low concentration of Stsp for several days to maintain this level and produce $\mathrm{a} G 1$ arrest in tissues such as bone marrow and intestinal mucosa.

\section{ACKNOWLEDGMENTS}

The authors express their gratitude to J. G. Valdez, D. C. Archuleta, and N. M. Lehnert for their technical contributions during the course of this study. This work was conducted under the auspices of the United States Department of Energy, Office of Health and Environmental Research.

\section{REFERENCES}

1. M. G. Ord and L. A. Stocken, "Variations in the Phosphate Content and Thiol/Disulphid Ratio of Histones During the Cell Cycle," Biochem. J. 107, p. 403 (1968).

2. L. R. Gurley and R. A. Walters, "The Response of Histone Turnover and Phosphorylation to X-Irradiation," Biochemistry 10, p. 1588 (1971).

3. R. Balhorn, M. Balhorn, H. P. Morris, and R. Chalkley, "Comparative HighResolution Electrophoresis of Tumor Histones: Variations in Phosphorylation as a Function of Cell Replication Rate," Cancer Res. 32, p. 1775 (1972).

4. L. R. Gurley, R. A. Walters, and R. A. Tobey, "The Metabolism of Histone fractions. VI. Differences in the Phosphorylation of Histone Fractions During the Cell Cycle," Arch. Biochem. Biophys. 154, p. 212 (1973).

5. L. R. Gurley, R. A. Walters, and R. A. Tobey, "Histone Phosphorylation in Late Interphase and Mitosis," Biochem. Biophys. Res. Commun. 50, p. 744 (1973).

6. E. M. Bradbury, R. J. Inglis, H. R. Matthews, and N. Sarner, "Phosphorylation of Very-Lysine-Rich Histone in Physarum polycephalum: Correlation with Chromosome Condensation," Eur. J. Biochem 33, p. 131 (1973). 
7. L. R. Gurley, R. A. Walters, and R. A. Tobey, "Cell Cycle-Specific Changes in Histone Phosphorylation Associated with Cell Proliferation and Chromosome Condensation," J. Cell Biol. 60, p. 356 (1974).

8. W. T. Garrard, G. H. Kidd, and J. Bonner, "Histone Phosphorylation During Liver Regeneration," Biochem. Biophys. Res. Commun. 70, p. 1219 (1976).

9. P. Hohmann, R. A. Tobey, and L. R. Gurley, "Phosphorylation on Distinct Regions of f1 Histone. Relationship to the Cell Cycle," J. Biol. Chem. 251, p. 3685 (1976).

10. L. R. Gurley, J. A. D'Anna, S. S. Barham, L. L. Deaven, and R. A. Tobey, "Histone Phosphorylation and Chromatin Structure During Mitosis in Chinese Hamster Cells," Eur. J. Biochem. 84, p. 1 (1978).

11. L. R. Gurley, R. A. Tobey, R. A. Walters, C. E. Hildebrand, P. G. Hohmann, J. A. D'Anna, S. S. Barham, and L. L. Deaven, "Histone Phosphorylation and Chromatin Structure in Synchronized Mammalian Cells," in Cell Cycle Regulation, J. R. Jetter, Jr., et al., Eds. (Academic Press, New York, 1978), p. 37.

12. L. R. Gurley, J. A. D'Anna, M. S. Halleck, S. S. Barham, R. A. Walters, J. J. Jett, and R. A. Tobey, "Relationships between Histone Phosphorylation and Cell Proliferation," in Cold Spring Harbor Conferences on Cell Proliferation, Vol. 8, Protein Phosphorylation, O. M. Rosen and E. G. Krebs, Eds. (Cold Spring Harbor Laboratory, Cold Spring Harbor, NY, 1981) p. 1073.

13. H. A. Crissman, D. M. Gadbois, R. A. Tobey, and E. M. Bradbury, "Transformed Mammalian Cells are Deficient in Kinase-mediated Control of Progression Through G1 Phase of the Cell Cycle," Proc. Nat. Acad. Sci. USA 88, p. 7580 (1991).

14. J. M. Kim, D. C. Archuleta, N. M. Lehnert, H. A. Crissman, L.R. Gurley, E. M. Bradbury, and B. E. Lehnert, "In vivo and In Vitro Effects of Staurosporine on the DNA Distributions and Proliferation of Various Rodent Cell Populations," Los Alamos National Laboratory report (in preparation).

15. G. J. Fallick and C. W. Rausch, "Radial Compression Separation System. An Advance in Analytical LC Column Technology,"Am. Lab. 11, p. 87 (Nov. 1979).

16. L.R. Gurley, J.A. D'Anna, M. Blumenfeld, J.G. Valdez, R. J. Sebring, P.R. Donahue, D. A. Prentice, and W.D. Spall, "Preparation of Histone Variants and HighMobility Group Proteins by Reversed-Phase High-Performance Liquid Chromatography," J. Chromatography 297, p. 147 (1984).

17. L.R. Gurley, J.S. Buchanan, J. E. London, D.M. Stavert, and B.E. Lehnert, "HighPerformance Capillary Electrophoresis of Proteins from the Fluid Lining of the Lungs of Rats Exposed to Perfluoroisobutylene," J. Chromatography 559, p. 411 (1991).

18. L.R. Gurley, W.D. Spall, J.G. Valdez, P.S. Jackson, J. Meyne, F.A. Ray, D. Prentice, and M. Blumenfeld, "HPLC of Histones" in HPLC of Biological Macromolecules, K.M. Gooding and F.E. Regnier, Eds. (Marcel Dekker, Inc., NY, 1990) p. 529. 
19. L.R. Gurley, W.D. Spall, J.G. Valdez, J.E. London, L.A. Dethloff, and B.E. Lehnert, "An HPLC Procedure for the Analysis of Proteins in Lung Lavage Fluid," Anal. Biochem. 172, p. 465 (1988).

20. J.C. Seagrave, J.G. Valdez, R.A. Tobey, and L.R. Gurley, "Melphalan Metabolism in Cultured Cells," Los Alamos National Laboratory report LA-10442-MS (1985).

21. L.R. Gurley, J.E. London, G.L. Tietjen, A.J. van der Kogel, L.A. Dethloff, and B.E. Lehnert, "Lung Hyperpermeability and Changes in Biochemical Constituents in Bronchoalveolar Lavage Fluids Following X-Irradiation of the Thorax," Radiat. Res. 134, p. 151 (1993).

22. L.R. Gurley, J.G. Valdez, W.D. Spall, B.F. Smith, and D.D. Gillett, "Proteins in the Fossil Bone of the Dinosaur, Seismosaurus," J. Protein Chem. 10, p. 75 (1991). 